\title{
GATEWAY
}

Demonstrations

\section{Color Maintenance of LEDs in Laboratory and Field Applications}

September 2013

Prepared for:

Solid-State Lighting Program

Building Technologies Office

Office of Energy Efficiency and Renewable Energy

U.S. Department of Energy

Prepared by:

Pacific Northwest National Laboratory 


\title{
DISCLAIMER
}

This report was prepared as an account of work sponsored by an agency of the United States Government. Neither the United States Government nor any agency thereof, nor Battelle Memorial Institute, nor any of their employees, makes any warranty, express or implied, or assumes any legal liability or responsibility for the accuracy, completeness, or usefulness of any information, apparatus, product, or process disclosed, or represents that its use would not infringe privately owned rights. Reference herein to any specific commercial product, process, or service by trade name, trademark, manufacturer, or otherwise does not necessarily constitute or imply its endorsement, recommendation, or favoring by the United States Government or any agency thereof, or Battelle Memorial Institute. The views and opinions of authors expressed herein do not necessarily state or reflect those of the United States Government or any agency thereof.

\author{
PACIFIC NORTHWEST NATIONAL LABORATORY \\ operated by \\ BATTELLE \\ for the \\ UNITED STATES DEPARTMENT OF ENERGY \\ under Contract DE-AC05-76RL01830
}

Printed in the United States of America

Available to DOE and DOE contractors from the

Office of Scientific and Technical Information,

P.O. Box 62, Oak Ridge, TN 37831-0062;

ph: (865) 576-8401

fax: $(865) 576-5728$

email: reports@adonis.osti.gov

Available to the public from the National Technical Information Service

5301 Shawnee Rd., Alexandria, VA 22312

ph: (800) 553-NTIS (6847)

email: orders@ntis.gov $<$ http://www.ntis.gov/about/form.aspx $>$

Online ordering: http://www.ntis.gov 


\title{
Color Maintenance of LEDs in Laboratory and Field Applications
}

\author{
Michael Royer, ${ }^{1}$ Ralph Tuttle, ${ }^{2}$ Scott Rosenfeld, ${ }^{3}$ Naomi Miller $^{1}$ \\ ${ }^{1}$ Pacific Northwest National Laboratory, Portland, OR \\ ${ }^{2}$ Cree, Inc., Durham, NC \\ ${ }^{3}$ Smithsonian Institution, Washington, DC
}

September 2013

PNNL-22759

\begin{abstract}
To date, consideration for parametric failure of LED products has largely been focused on lumen maintenance. However, color shift is a cause of early failure for some products, and is especially important to consider in certain applications, such as museum lighting, where visual appearance is critical. Field data collected by the U.S. Department of Energy's (DOE) GATEWAY program for LED lamps installed in museums shows that many have changed color beyond a reasonable tolerance well before their rated lifetimes have been reached. Laboratory data collected by DOE's CALiPER program between 2008 and 2010 reveals that many early LED products shifted beyond acceptable tolerances in as little as a few thousand hours. In contrast, data from the L Prize ${ }^{\circledR}$ program illustrates that commercially available LED products can have exemplary color stability that is unmatched by traditional light sources.

In addition to presenting data from the aforementioned DOE programs, this report discusses the metrics used for communicating color shift, and provides guidance for end users on how to monitor chromaticity and what to look for in manufacturer warranties. Also covered are the physical changes that have been shown to lead to color shift in some types of LED packages. As with lamps and luminaires, the data presented for LED packages shows that a wide variety of products are available; in order for specifiers and consumers to make educated choices, more detailed and standardized information is necessary.
\end{abstract}

\section{Keywords}

Light-emitting diode (LED), color shift, color stability, color maintenance, warranty 


\section{Introduction}

The stability of a lighting product's spectral output over time is a critical aspect of high quality lighting. Changing spectral output-typically referred to as color shift-affects not only the color appearance of the emitted light, but potentially also the color of objects the source is illuminating. Multiple light sources that shift in variable ways can result in distracting patterns, and collective shifts can result in an overall undesirable appearance. Either situation degrades the visual environment.

While in some applications large color tolerances may be acceptable, specifiers of lighting for inherently visual environments, such as museums or patient examination rooms, must carefully consider the color maintenance of light sources. The same can be said for applications that require numerous lamps or luminaires to evenly illuminate a relatively monochromatic surface, such as a building façade or architectural cove. If the output of a light source changes in color too much over time, it can no longer be used, thus constituting a parametric failure of the product. Although just as important as lumen depreciation (i.e., $L_{70}$ ) or catastrophic failure, color shift is less frequently considered as a failure mechanism.

The term color stability refers to a lamp's ability to maintain a spectral power distribution over time. It is separate from color consistency, which refers to the initial lamp-to-lamp variation in spectral power distribution. Changes in spectral output resulting from changes to the ambient environment are also a distinct issue, as is depreciation in radiant flux. However, all of these different issues may be interrelated.

Color stability is a concern for all types of light sources, and performance varies between (and within) different technologies. Halogen lamps are generally regarded as stable, whereas fluorescent lamps can vary based on environmental conditions, but are generally stable in steady-state operation. Metal halide lamps are notorious for poor color maintenance over time, although ceramic metal halide lamps may offer some improvement. With increased adoption of LED products-and increasing hours of useawareness is growing that color shift may be an issue for some products. While improvements are being made at the package and complete product levels, there is little publicly available information on the extent to which LED products can be expected to maintain their spectral power distribution over time, especially beyond 6,000 hours of operation.

This report provides color shift data for LED lamps used in real-world applications, as well as for LED products monitored in a laboratory environment. It also includes some color shift data for example LED packages. The document describes the known mechanisms of color shift, and provides end users with guidance on how to monitor performance, as well as what to look for in a product warranty. Finally, it looks at the development of new standards that may help manufacturers understand and communicate expected performance over time. 


\section{Background}

The color of a light source is often described using chromaticity coordinates, a basic principle of the CIE system of colorimetry [CIE 2004], or a metric derived from them. The chromaticity coordinates of a source provide a numerical representation of the color of the light, but offer little indication of how the source will render specific object colors-changes to the chromaticity coordinates of a light source will lead to changes in the appearance of rendered objects.

Chromaticity diagrams are relative plots of hue and saturation-regardless of lightness, which is discarded as a third dimension. In essence, they are two dimensional representations of a three-dimensional color space that is derived from color matching functions. Subsequently developed three-dimensional color spaces (CIELAB and CIELUV) are more appropriate for describing object colors and absolute appearance, whereas chromaticity diagrams are sufficient for describing the output of light sources.

As the CIE system of colorimetry has developed, the way in which chromaticity is plotted has been transformed to create a closer match to visual evaluations of color difference. That is, the plotted distance between two sets of color pairs with equal visual difference is intended to be the same. The three most commonly referenced chromaticity diagrams are the CIE 1931 ( $x$, y), $\operatorname{CIE} 1960 \operatorname{UCS}^{1}(u, v)$, and CIE $1976 \operatorname{UCS}\left(u^{\prime}, v^{\prime}\right)$, as shown in Figure 1 . While $(x, y)$ coordinates are most frequently reported, color shift is most appropriately documented as the difference or change in $\left(u^{\prime}, v^{\prime}\right)$ coordinates, written $\Delta u^{\prime} v^{\prime}$, because the $\left(u^{\prime}, v^{\prime}\right)$ chromaticity diagram is the most visually uniform. Nonetheless, no available chromaticity diagram is a perfect representation of human color perception, which itself varies from person to person. For many years, research has been ongoing to improve the methods used for documenting color difference, but as with many lighting concepts, older methods remain important for commerce.

Correlated color temperature (CCT) and $\mathrm{D}_{\mathrm{uv}}$ are measures of light source color appearance derived from

\footnotetext{
${ }^{1}$ UCS is an abbreviation of Uniform Chromaticity Scale.
}
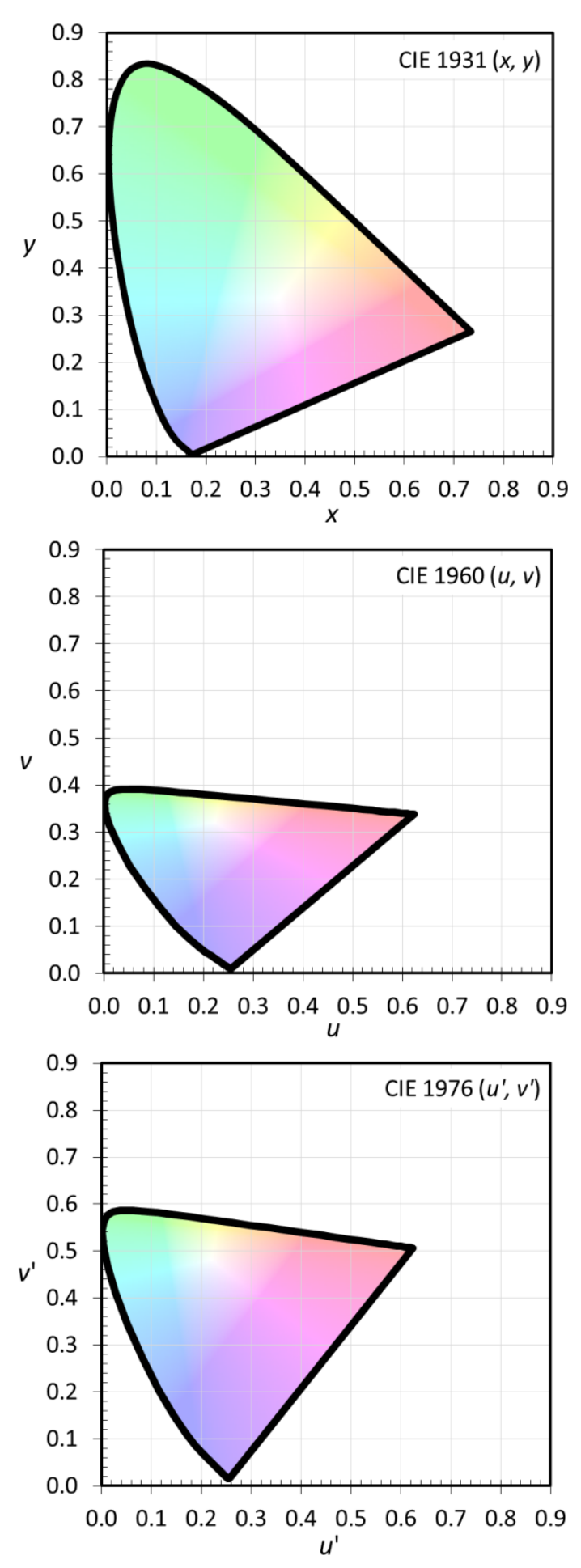

Figure 1. CIE $2^{\circ}$ chromaticity diagrams. The 1960 and 1976 versions are linear transformations of the original 1931 version. The colored backgrounds are shown for orientation only. 
chromaticity coordinates. CCT and $\mathrm{D}_{\mathrm{uv}}$ values are calculated using the CIE $1960(u, v)$ chromaticity diagram (see Figure 2) due to the timing of the development of CCT, although the concepts are applicable in any chromaticity diagram. Either measure alone cannot accurately describe the exact color appearance of a source, but when used together the measures can be thought of as a two-dimensional coordinate system with (somewhat) visually meaningful axes. In rough terms, CCT describes a yellowblue axis, and $D_{u v}$ describes a red-green axis. Nonetheless, reporting color shift as the change in one or both of these values is insufficient for characterizing the magnitude of the perceptual difference, especially since the $(u, v)$ chromaticity diagram is not as perceptually uniform as its successor, $\left(u^{\prime}, v^{\prime}\right)$.

Chromaticity "bins" demarcate areas on a chromaticity diagram, and are often used by manufacturers to sort products and convey nominal performance. Quadrangular bins for nominal CCT are defined by the American National Standards Institute (ANSI) Lighting Group and National Electrical Manufacturers Association (NEMA) document C78.377-2011 [ANSI 2011], as shown in Figure 3. These quadrangles only roughly represent color appearance, and the variation within a bin is noticeable and unsatisfactory for almost all applications. That is, a source at one edge of the bin will appear very different from a source at the other end. Accordingly, manufacturers often establish much finer bins for sorting their products. Like with CCT and $\mathrm{D}_{\mathrm{uv}}$ - as well as any color rendering metric, such as the Color Rendering Index (CRI)color bins have little relevance to color shift, other than being gross representations of light sources with different color temperatures.

\section{Color Difference Concepts}

Color difference and the limits of human color tolerance are complex topics that receive considerable attention in research communities. Modern work in this field started with MacAdam ellipses, and although alternative concepts are now available, the principles are often related the original ellipses. The $\Delta u^{\prime} v^{\prime}$ formula is currently recommended for describing color difference or color shift for light sources, and many variants of $\Delta \mathrm{E}$ (e.g., $\Delta \mathrm{E}^{*}{ }_{\mathrm{ab}}, \Delta \mathrm{E}^{*}{ }_{94}, \Delta \mathrm{E}^{*}{ }_{00}$, or $\Delta \mathrm{E}^{*}{ }_{\mathrm{cmc}}$ ) are used to describe color difference of objects.

\section{MacAdam Ellipses}

In lighting literature, color difference is frequently described using MacAdam ellipses, although they are

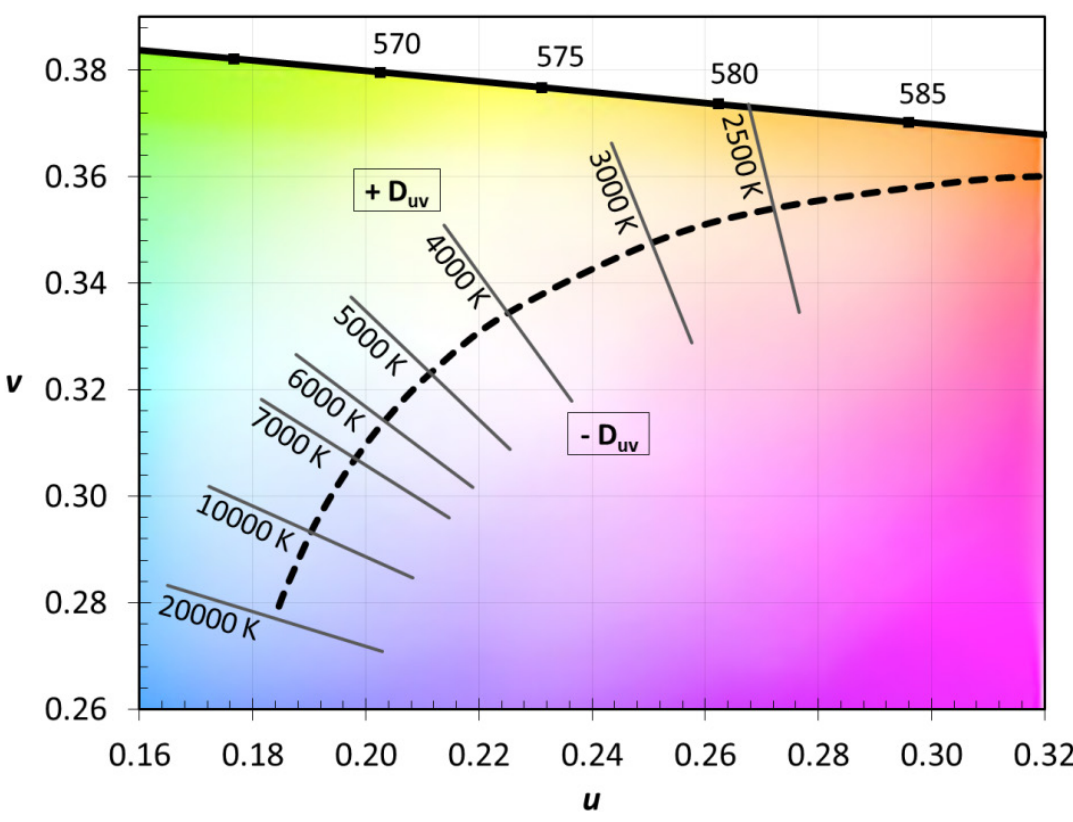

Figure 2.

A close-up of the CIE 1960 UCS, showing lines of constant CCT, which were designed to be perpendicular to the black body locus in that particular diagram. At a given $\mathrm{CCT}$, a source with a positive value for $D_{u v}$ has a chromaticity that falls above the black body locus (appearing slightly greenish), whereas a source with a negative value for $D_{u v}$ has a chromaticity that falls below the black body locus (appearing slightly pinkish). The lines in this chart represent a $D_{u v}$ range of \pm 0.02 , which is much greater than ANSI tolerances for white light. 
widely misunderstood. MacAdam ellipses were developed under strict experimental procedures, with the ellipse representing a standard deviation of color matching (SDCM) for a single highly trained observer who made repeated matches [MacAdam 1942]. These ellipses were derived throughout the $1931(x, y)$ chromaticity diagram, and the conspicuous difference in size influenced subsequent chromaticity diagram revisions (see Figure 3 ). As shown in Figure 4 , in the $\left(u^{\prime}, v^{\prime}\right)$ chromaticity diagram, the ellipses are approximately circles, with a one-step ellipse having a radius of about 0.001 -at least in the region around the black body locus (nominally white light).

MacAdam ellipses are often reported with a step size (e.g., seven-step), which is in reference to the multiple of the original SDCM ellipse. In this way, two pairs of chromaticity coordinates can be said to represent an x-step difference. Importantly, MacAdam's ellipses characterized the difference between the point at the center of the ellipse and a point at the edge of the ellipse, not two points at the edge. Thus, two points at opposite ends of a seven-step ellipse are correctly characterized as exhibiting a 14step difference (see Figure 3).

A common misinterpretation of MacAdam ellipses is that they are universally related to a just-noticeable difference. Under the conditions of MacAdam's experiment, a three-step difference was determined to be just noticeable [Wyszecki 1982], but that inference cannot be extrapolated to other environmental conditions that are drastically different from the small field of view under which the research was conducted. The noticeability of a difference in chromaticity depends on many factors; for example, two adjacent lamps aimed at a white wall might appear to be different colors, but when used in downlights at the opposite ends of a room, the difference might not be apparent. Further, as is the case with all lighting metrics, chromaticity and color difference formulas are based on average observers, so individual perceptions may vary.
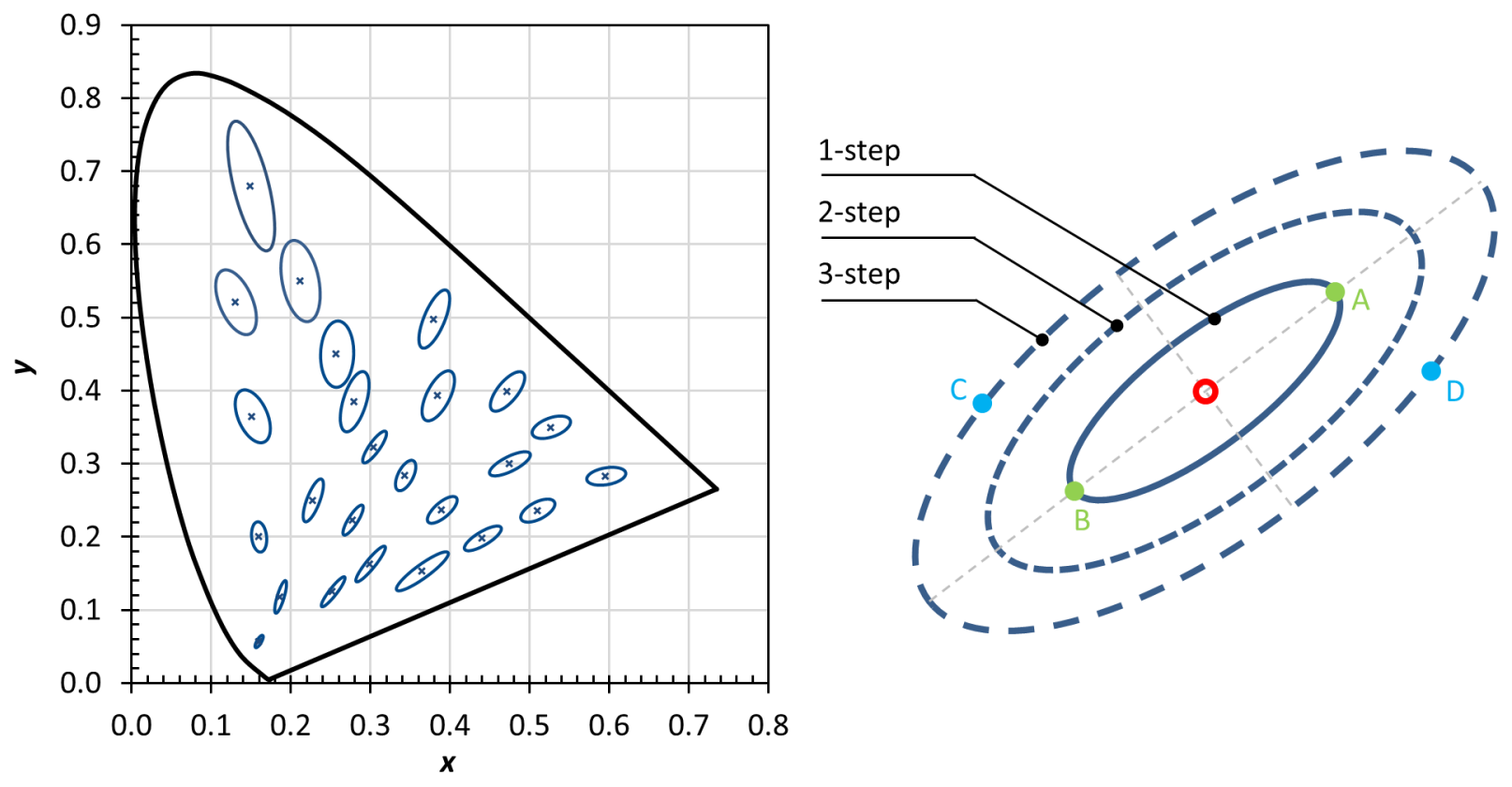

Figure 3. Left: 10-step MacAdam ellipses plotted in the $1931(x, y)$ chromaticity diagram. The different sizes of the ellipses illustrate the nonuniformity of the diagram.

Right: Enlarged image of a typical ellipse. An x-step difference is always relative to the target chromaticity (center of the ellipse). Point $A$ is one step different from the target, but two steps different from point $B$. In other words, all points encompassed by an ellipse (e.g., points $C$ and $D$ ) are not within the specified step size tolerance of each other, but only with $\mathrm{n}$ the step size tolerance of the center point. 


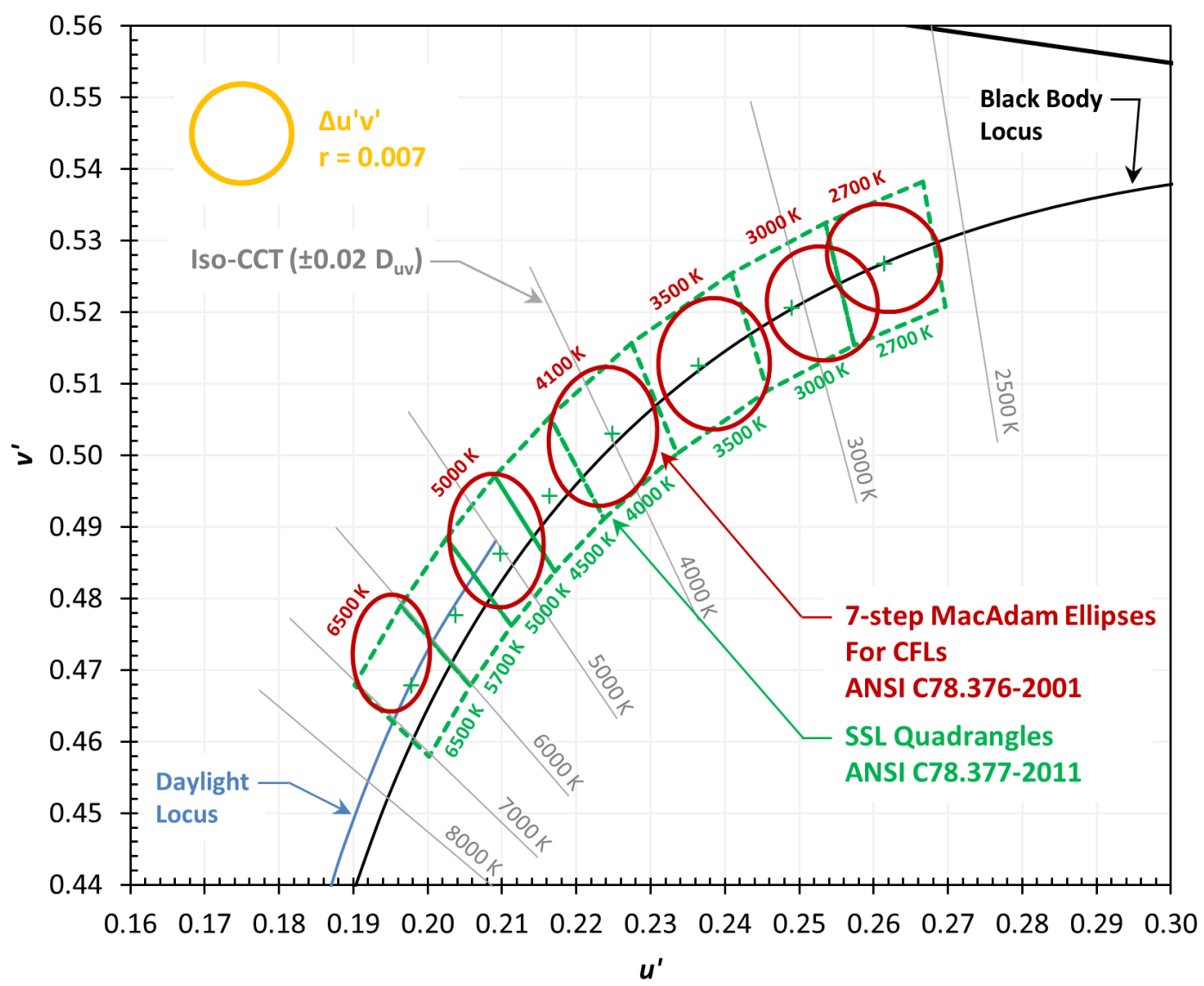

Figure 4. ANSI tolerances for CFL and SSL sources in the $\mathbf{1 9 7 6}\left(\boldsymbol{u}^{\prime}, \boldsymbol{v}^{\prime}\right)$ chromaticity diagram. For this diagram, MacAdam ellipses are approximately circular around the black body locus, with one step equal to approximately 0.001 .

$\Delta u^{\prime} \mathbf{v}^{\prime}$

Determining MacAdam ellipses requires several formulas, whereas $\Delta u^{\prime} v^{\prime}$ is simply calculated as the Euclidian distance between a pair of chromaticity coordinates in the $\left(u^{\prime}, v^{\prime}\right)$ chromaticity diagram. The relationship to MacAdam ellipses in the region around the black body locus - as previously describedallows for the approximation that a $\Delta u^{\prime} v^{\prime}$ value of 0.001 is equivalent to a one-step difference. As with MacAdam ellipses, however, the noticeability of a difference is dependent on many factors, so there is no universal limit for what is considered an acceptable $\Delta u^{\prime} v '$.

Given the mathematical simplicity of specifying color shift limits in terms of $\Delta u^{\prime} v^{\prime}$ and the rather complex procedure for calculating a MacAdam ellipse-not to mention the many common misconceptions-both manufacturers and specifiers may benefit from using the $\Delta u^{\prime} v$ ' terminology. One important fact to remember, however, is that neither MacAdam ellipses nor $\Delta u^{\prime} v^{\prime}$ communicate anything about the direction of the color shift, which may or may not be important. Rather, $\Delta u^{\prime} v^{\prime}$ quantifies the total color difference that may be the result of changes to either $D_{\mathrm{uv}}$ or CCT (or any other two-dimensional representation of chromaticity), as shown in Figure 5.

\section{Existing Standards for Measuring and Documenting Color Shift}

The Illuminating Engineering Society's (IES) LM-80-08, Measuring Lumen Maintenance of LED Light Sources [IES 2008], prescribes an approved method for long-term measurement of LED packages-but not complete LED lamps or luminaires (that document is in progress). While it primarily targets lumen maintenance, LM-80-08 requires that chromaticity shift be measured (and subsequently reported) over the course of the test procedure, which must last a minimum of 6,000 hours. There are no specified acceptable limits for color shift, and there is no method for projecting future color shift as there is for 


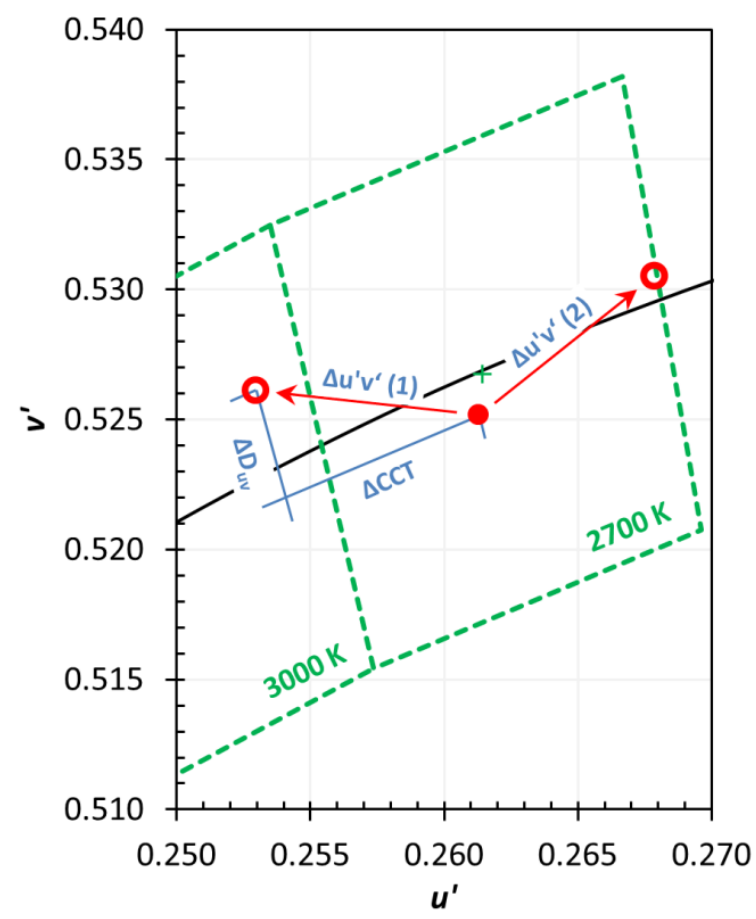

Figure 5. Close-up of the $1976\left(u^{\prime}, v^{\prime}\right)$ chromaticity diagram illustrating the difference between $\Delta \mathbf{u}^{\prime} \mathbf{v}^{\prime}, \Delta \mathbf{D}_{\mathrm{uv}}$, and $\Delta \mathrm{CCT}$. $\Delta \mathrm{D}_{\mathrm{uv}}$ and $\Delta \mathrm{CCT}$ are insufficient for characterizing color difference. Only $\Delta u^{\prime} v$ ' describes the total color difference that might be observed, although it does not describe the direction of the shift. As such, $\Delta u^{\prime} v^{\prime}(1)$ and $\Delta u^{\prime} v^{\prime}(2)$ would have the same value, despite shifting in different directions.

lumen depreciation (IES TM-21-11 [IES 2011]). One important note with LM-80-08 is that the ambient air temperature and solder point temperature of the LED package are at equilibrium, which is unlikely to mimic real-world operating conditions.

The ENERGY STAR ${ }^{\circledR}$ program does mandate that $\Delta u^{\prime} v^{\prime}$ at 6,000 hours of operation not exceed 0.007 [EPA $2012,2013]$. This is perhaps the only industry-wide criterion for color shift. It is a reasonable starting point, but may not be strict enough to ensure very high-quality lighting, especially since the lifetimes of LED products routinely far exceed 6,000 hours.

Although more critical for color consistency than color stability, it is important to note that the quadrangles defined by ANSI/NEMA offer very large tolerances for nominal CCTs. For example, the

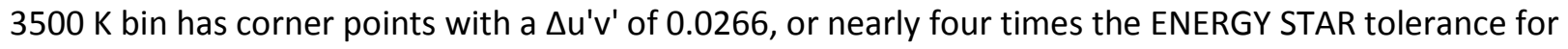
color shift. Needless to say, two lamps with the same nominal CCT designation can appear vastly different, and the difference can be exacerbated by color shift over time. Many LED chip manufacturers can offer much finer bins than the nominal CCT tolerances established in C78.377-2011. 


\section{Color Shift Data}

The data presented here, which is conglomerated from several DOE efforts, collectively provides an understanding of the current state of the market and helps to identify a path toward improving the color stability of future products. However, the data has largely been analyzed post-hoc, and much of the work was never intended to be a rigorous scientific investigation of color shift. It is possible that analyzing different products under different conditions would provide different results. However, the information presented illustrates both the high potential for LED lighting and some of the hurdles that must be overcome.

\section{DOE GATEWAY Program Data}

The GATEWAY program has featured three museum projects, including a recent collaboration with the Smithsonian American Art Museum in Washington, DC [DOE 2012]. Museums are particularly demanding for lighting, especially with regard to color appearance and color maintenance. While GATEWAY demonstration projects typically focus on the initial performance and expected payback of LED lighting systems, the LED lamps installed at the Smithsonian were reevaluated after several thousand hours of use when color shift became apparent.

Many different lamps were installed as part of the Smithsonian GATEWAY project-and in subsequent additional trials. As some of the lamps have aged, they have shifted in visually noticeable ways, in some cases requiring replacement well before the lamps' rated lifetimes. While there was a strong tendency for lamps that used the same LED chips and that were placed in the same environment to shift as a group, it is common for manufacturers to use different chips depending on the specific lamp performance (e.g., different luminous intensity distribution). Very small die used for narrow spot lamps may shift differently from larger-die flood lamps from the same manufacturer-as was also experienced at the Smithsonian. Importantly, the premature failures due to color shift happened independent of lumen depreciation or catastrophic failure. Warranty coverage for color stability problems ranged from manufacturers that explicitly provided coverage, to manufacturers that were willing to remedy the problem once they received a complaint, to manufacturers that were unresponsive.

Because the initial intent of the Smithsonian GATEWAY project was not to document performance over time, no procedure was followed to track the performance of any given lamp (i.e., to record longitudinal data). Rather, individual lamps with varying hours of operation were analyzed post-hoc once color shift issues were identified. That is, values for $\Delta u^{\prime} v$ ' were calculated for aged lamps relative to new lamps of the same type, rather than for the aged lamp versus itself when it was new. The lamps ranged up to 6,600 hours of operation, typically in a cylinder-style trackhead that sometimes had additional optical elements such as a lens, louver, or screen in front of the lamp.

During installation, the Smithsonian evaluated all of the lamps to visually confirm that none was noticeably different. Additionally, during specification, lamps were tested to confirm that the color was uniform across the beam (color over angle). These actions add some credibility to the method of comparing aged lamps to new lamps of the same type, although the data must still be used cautiously.

The GATEWAY program has also collected and measured lamps from the Hallie Ford Museum of Art at Willamette University, an installation that was not part of a GATEWAY demonstration. The Smithsonian and Hallie Ford projects are indicative of wider trends that have been reported throughout the museum community, which serves as a vital test bed for LED technology. 
Table 1. GATEWAY data on color from lamps used in museums.

\begin{tabular}{|c|c|c|c|c|c|c|c|}
\hline Type & Description & $\begin{array}{l}\text { Hours } \\
\text { of Use }\end{array}$ & $\begin{array}{c}\text { Relative } \\
\text { Output }\end{array}$ & CCT & $D_{u v}$ & $\Delta u^{\prime} v^{\prime} T_{i m e}^{2}$ & $\Delta u^{\prime} v^{\prime}$ Optics ${ }^{3}$ \\
\hline A1 & PAR30, $10^{\circ}, 2700 \mathrm{~K}$ & 0 & - & 3063 & -0.0032 & - & 0.0007 \\
\hline A1 & PAR30, $10^{\circ}, 2700 \mathrm{~K}$ & 100 & $92 \%$ & 3066 & -0.0028 & $0.0005^{1}$ & No Data \\
\hline A1 & PAR30, $10^{\circ}, 2700 \mathrm{~K}$ & 5,750 & $100 \%$ & 2949 & 0.0022 & $0.0100^{1}$ & No Data \\
\hline A1 & PAR30, $10^{\circ}, 2700 \mathrm{~K}$ & 6,600 & $97 \%$ & 2990 & 0.0007 & $0.0070^{1}$ & No Data \\
\hline $\mathrm{A} 1$ & PAR30, $10^{\circ}, 2700 \mathrm{~K}$ & 6,600 & $90 \%$ & 3020 & 0.0005 & $0.0060^{1}$ & No Data \\
\hline$A 2$ & PAR30, $25^{\circ}, 2700 \mathrm{~K}$ & 100 & - & 3008 & 0.0005 & - & 0.0003 \\
\hline $\mathrm{A} 2$ & PAR30, $25^{\circ}, 2700 \mathrm{~K}$ & 6,600 & $94 \%$ & 2922 & 0.0016 & $0.0052^{1}$ & 0.0003 \\
\hline $\mathrm{A} 2$ & PAR $30,25^{\circ}, 2700 \mathrm{~K}$ & 6,600 & $95 \%$ & 2928 & 0.0023 & $0.0058^{1}$ & No Data \\
\hline B1 & PAR38, $10^{\circ}, 2700 \mathrm{~K}$ & 0 & - & 2727 & -0.0020 & - & 0.0009 \\
\hline B1 & PAR38, $10^{\circ}, 2700 \mathrm{~K}$ & 4,000 & $103 \%$ & 2981 & 0.0008 & $0.0110^{1}$ & 0.0009 \\
\hline B2 & PAR38, $10^{\circ}, 2700 \mathrm{~K}$ & 0 & - & 2744 & -0.0024 & - & 0.0008 \\
\hline B2 & PAR38, $10^{\circ}, 2700 \mathrm{~K}$ & 4,000 & $91 \%$ & 2687 & 0.0029 & $0.0088^{1}$ & 0.0005 \\
\hline C & MR16, $2700 \mathrm{~K}$ & 0 & - & 2789 & -0.0024 & - & 0.0013 \\
\hline C & MR16, $2700 \mathrm{~K}$ & 5,000 & $78 \%$ & 2548 & 0.0054 & 0.0183 & 0.0004 \\
\hline $\mathrm{D}$ & MR16, $2700 \mathrm{~K}$ & 480 & - & 2771 & -0.0008 & - & 0.0017 \\
\hline D & MR16, $2700 \mathrm{~K}$ & 2,400 & $83 \%$ & 2655 & 0.0004 & 0.0062 & 0.0022 \\
\hline D & MR16, $2700 \mathrm{~K}$ & 2,400 & $81 \%$ & 2754 & 0.0043 & 0.0076 & 0.0021 \\
\hline
\end{tabular}

1. LM-80 data suggests a maximum shift of 0.035 at $85^{\circ} \mathrm{C}$ and $1000 \mathrm{~mA}$ drive current. The package used for product types $\mathrm{C}$ and $\mathrm{D}$ are unknown.

2. $\Delta u^{\prime} v^{\prime}$ was calculated relative to the baseline case, which was an unused version of the same lamp type (i.e., the first sample in each group). Red values exceed the ENERGY STAR criterion of 0.007 .

3. For each individual lamp with secondary optics removed compared to the same lamp before the optics were removed.

Table 1 provides data for a sample of lamps that the GATEWAY program has evaluated. These lamps were measured according to IES LM-79-08 at the Pacific Northwest National Laboratory (PNNL) photometry lab. They were operated and measured in open air (i.e., bare lamp). Each entry is for a unique product, with the approximate hours of use listed. Color shift was calculated relative to the first listed value for each product type. Many of the lamp samples had a $\Delta u^{\prime} v^{\prime}$ greater than 0.007 relative to the baseline sample, all in 6,600 hours or less.

Although the data was not collected from the same lamp samples over time, it is highly suggestive of substantial color shift, especially because the initial chromaticity coordinates were supported by manufacturer-supplied data, if available. In the subsequent analysis, the data is treated as approximating longitudinal data. Several plots of $1976\left(u^{\prime}, v^{\prime}\right)$ chromaticity diagrams are shown in Figure 6. These charts show that the measured shifts are primarily-but not always-toward a more yellow appearance.

In addition to evaluating bare lamps, secondary optical systems (e.g., plastic lens elements) were removed in order to isolate the performance of the LED package. Although at least one of the products showed visible discoloration of a physical material over time, removing the optical systems resulted in minimal changes to the measured chromaticity. ${ }^{2}$ Further, there was little difference in the total shift

\footnotetext{
${ }^{2}$ Upon further examination, the discoloration was of the white board on which the LEDs were mounted, rather than the lens.
} 
when removing the lens from the newer lamps or older lamps, as shown in Figure 6 . Thus, it is reasonable to conclude that the shifts are a result of changes to the LED packages.

A1

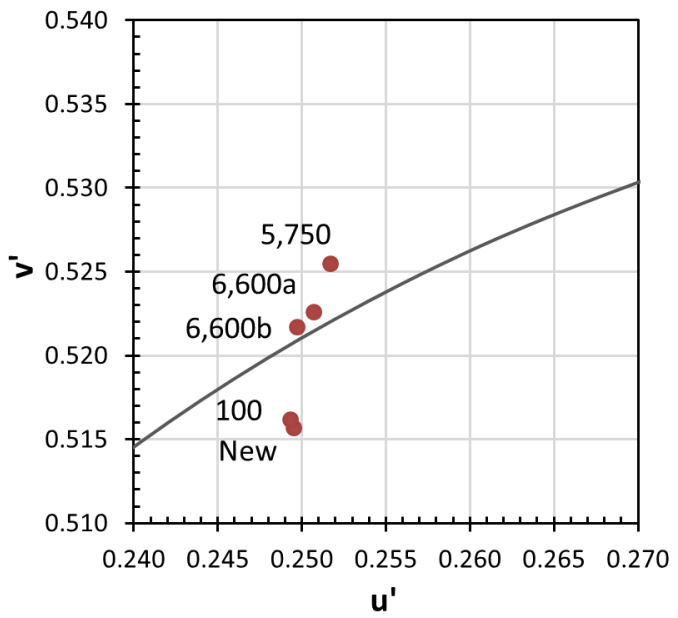

B1

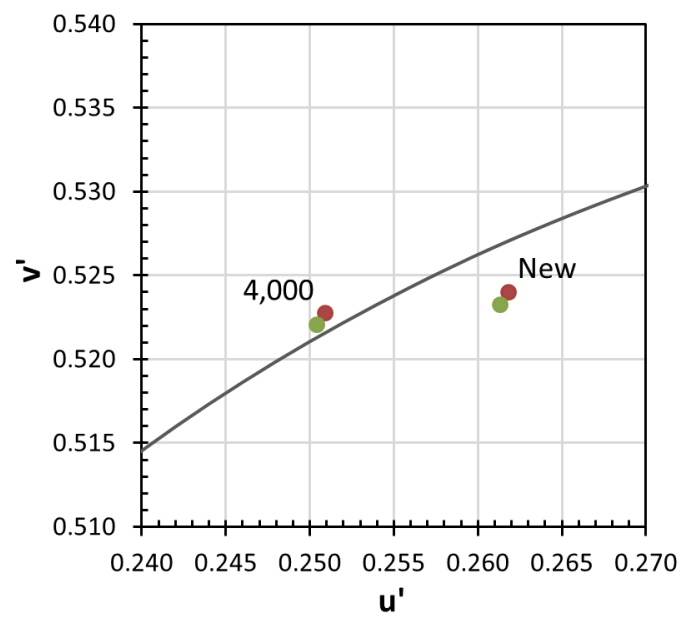

C1

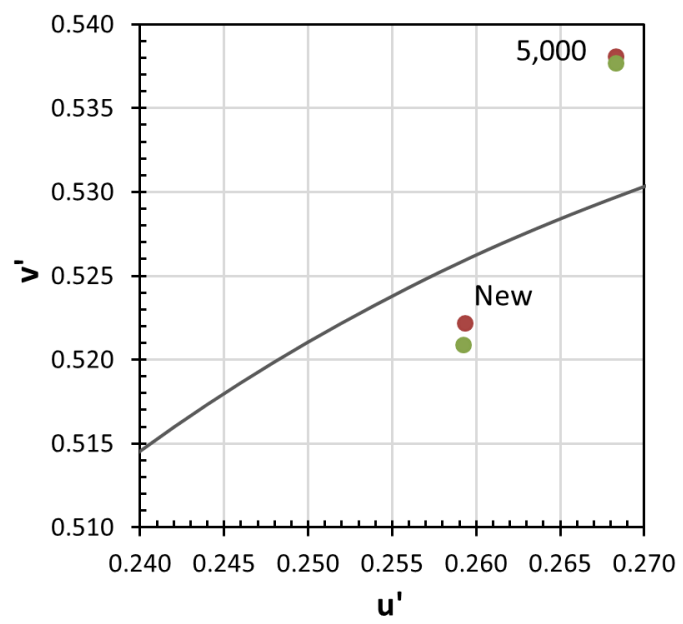

A2

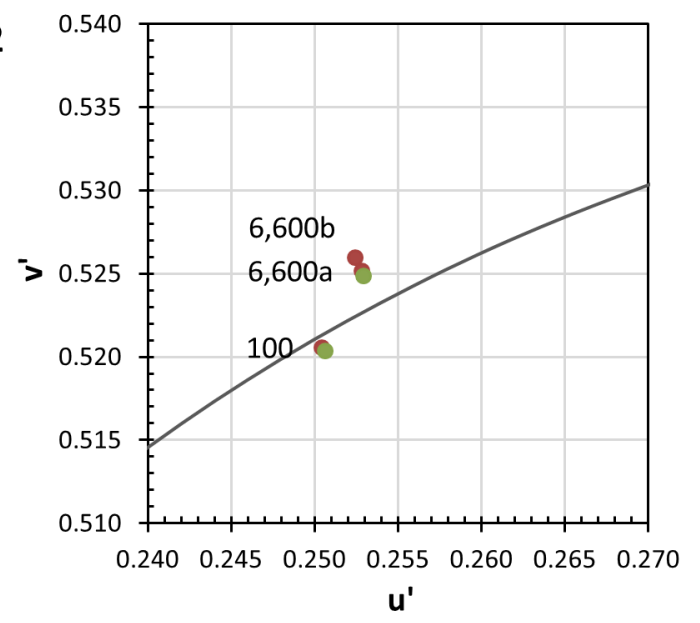

B2

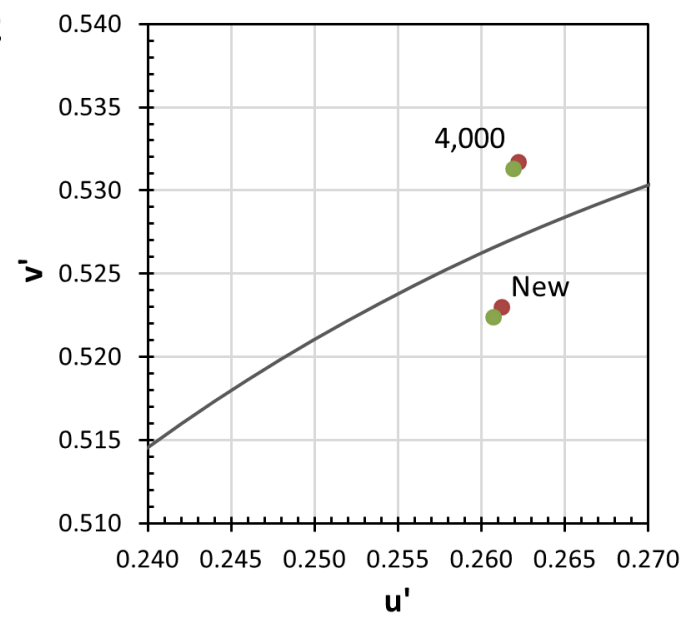

D1

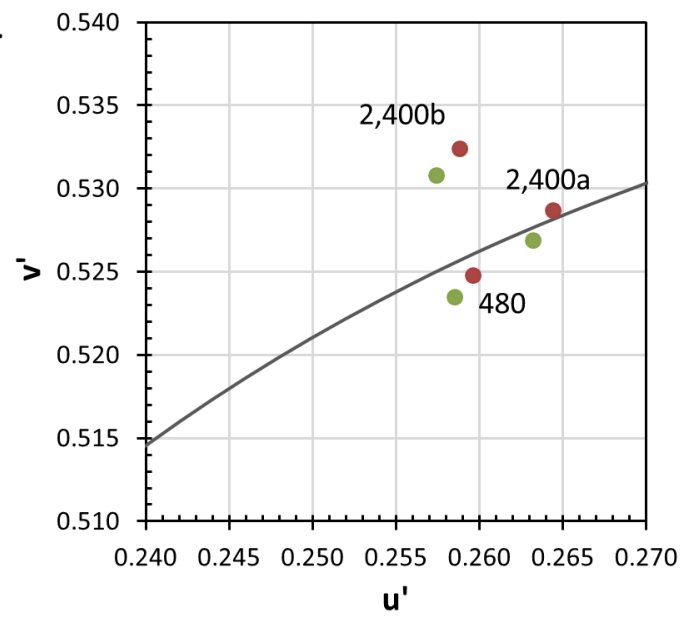

- Bare Lamp Bare Lamp with Secondary Optics Removed

Figure 6. Color shift of lamps used in GATEWAY demonstration projects, as shown in the $1976\left(u^{\prime}, v^{\prime}\right)$ chromaticity diagram. Each point is labeled with its hours of use. The data is not longitudinal. 
Importantly, the color shift observed in these lamps was not predicted by LM-80-08 test data (if available), which would suggest shifts at 6,000 hours of no more than $\Delta u^{\prime} v^{\prime}=0.0035$, depending on the exact package and operating conditions. At least in the case of lamp manufacturer $A$, the lamp and luminaire combination was approved (by the lamp manufacturer) after thermal testing in the manufacturer's laboratory before operation commenced, and field measurements of ambient temperature did not seem to be outside the range for LM-80-08 testing. This lamp also employed a thermistor to prevent thermal conditions from exceeding an acceptable range, thus preventing damage to the lamp (note that all data shown here was collected according to LM-79-08, so the output should not have been changed by the thermistor at the time of measurement). Additionally, the color shift was similarly unacceptable whether a glass lens was used or just an open louver, although this may have caused little difference in thermal environment because the trackheads had an enclosed back.

Figure 7 shows the change in SPD for lamp types B1 and B2. The 4,000-hour sample for lamp type B1 was generally more blue than the baseline sample, and emitted about $3 \%$ more lumens - again, the data is not longitudinal, meaning two different lamps with different hours of use were measured, and they did not necessarily start out the same. The blue peak in the aged SPD of lamp type B1 had more energy, whereas the yellow peak had less energy and was shifted to a slightly shorter wavelength. In contrast, lamp type B2 shifted toward yellow and emitted about $9 \%$ fewer lumens. Accordingly, the decrease in the amplitude of the blue peak was greater than the decrease in amplitude of the yellow peak.

Lamp types A1 and A2 were also measured in a sample trackhead of the same type used when they were operated in the field, both with and without an auxiliary glass lens (data not shown on plots). In both cases, the minimal color difference between the test condition and baseline was much less than observed based on hours of use, with about half attributable to operation in the luminaire and the other half attributable to adding the lens to the luminaire. In general, this shift was comparable to that measured when the secondary optical system was removed from the lamp, and was likely caused by changing the ambient temperature of the air immediately around the lamp.

\section{DOE CALiPER Program Data}

Between 2008 and 2010, the CALiPER program conducted long-term testing of approximately 50 complete LED lamps and luminaires at an independent photometric lab. While many improvements have been made to LED products in the past three years, this data is nonetheless valuable for understanding some of the mechanisms of color shift that remain a potential problem. A subset of the original data, which removes some products considered especially outdated (e.g., those using $5 \mathrm{~mm}$ LEDs) or that were tested using a different protocol, is included here.

After undergoing initial LM-79-08 testing in an integrating sphere, the products were mounted in an apparatus to allow for continuous operation at an ambient temperature of $25^{\circ} \mathrm{C}\left( \pm 5^{\circ} \mathrm{C}\right)$ and constant input voltage. Spot illuminance and chromaticity measurements were made every 500 hours using a handheld meter with a jig and masking apparatus for consistency. After 6,000 hours, the products were again measured in the same integrating sphere. Some products failed prior to 6,000 hours, and others underwent an additional 6,000-hour cycle. ${ }^{3}$

Figure 8 shows the initial and final chromaticity coordinates of the products, as measured in an integrating sphere according to LM-79-08. The products plotted in red underwent an additional 6,000 hours of testing, during which the color shift generally continued in the same direction. As shown, many of the products shifted along the blue-yellow axis, although there were a few exceptions. Products with

\footnotetext{
${ }^{3}$ Four lamps had an initial cycle of 7,500 hours instead of 6,000 hours.
} 

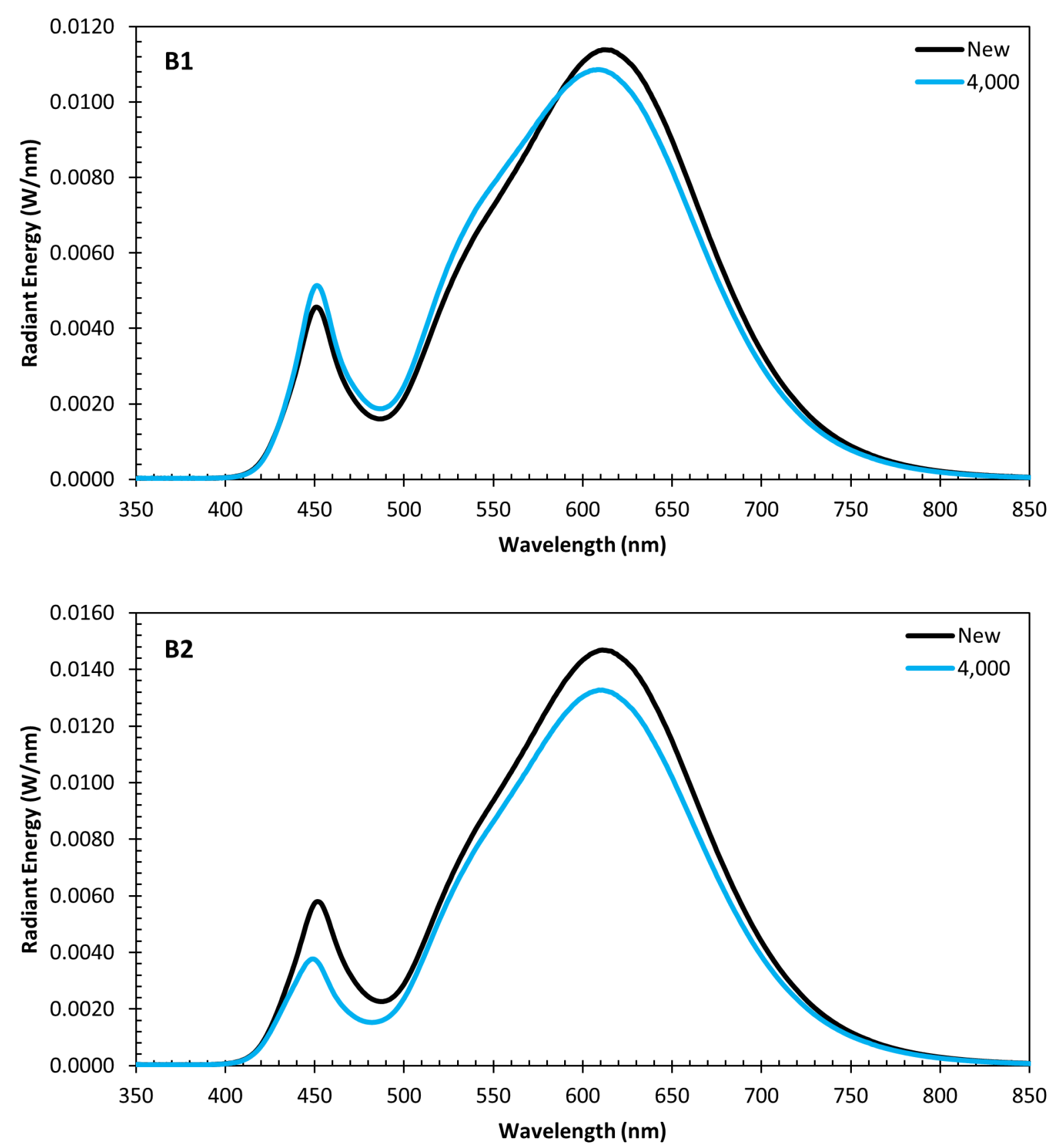

Figure 7. Spectral power distributions for new lamps compared to lamps that had been operated for 4,000 hours. Lamp type B1 was more blue at 4,000 hours than a new lamp of the same type, whereas lamp type B2 was more yellow.

a higher CCT were much more likely to exhibit greater color shift. In total, 15 of the 45 products listed had a $\Delta u^{\prime} v^{\prime}$ of more than 0.007 in the first 6,000 hours of operation. Other interesting observations include:

- Of the 15 products with a $\triangle \mathrm{u}^{\prime} \mathrm{v}^{\prime}$ exceeding 0.007 , eight had a CCT above $4500 \mathrm{~K}$. Only two of the ten products with a CCT above $4500 \mathrm{~K}$ did not exceed the ENERGY STAR $\Delta \mathrm{u}^{\prime} \mathrm{v}^{\prime}$ limit of 0.007 at 6,000 hours of operation (the lamps were not necessarily ENERGY STAR qualified, but that threshold is used as a reference). 


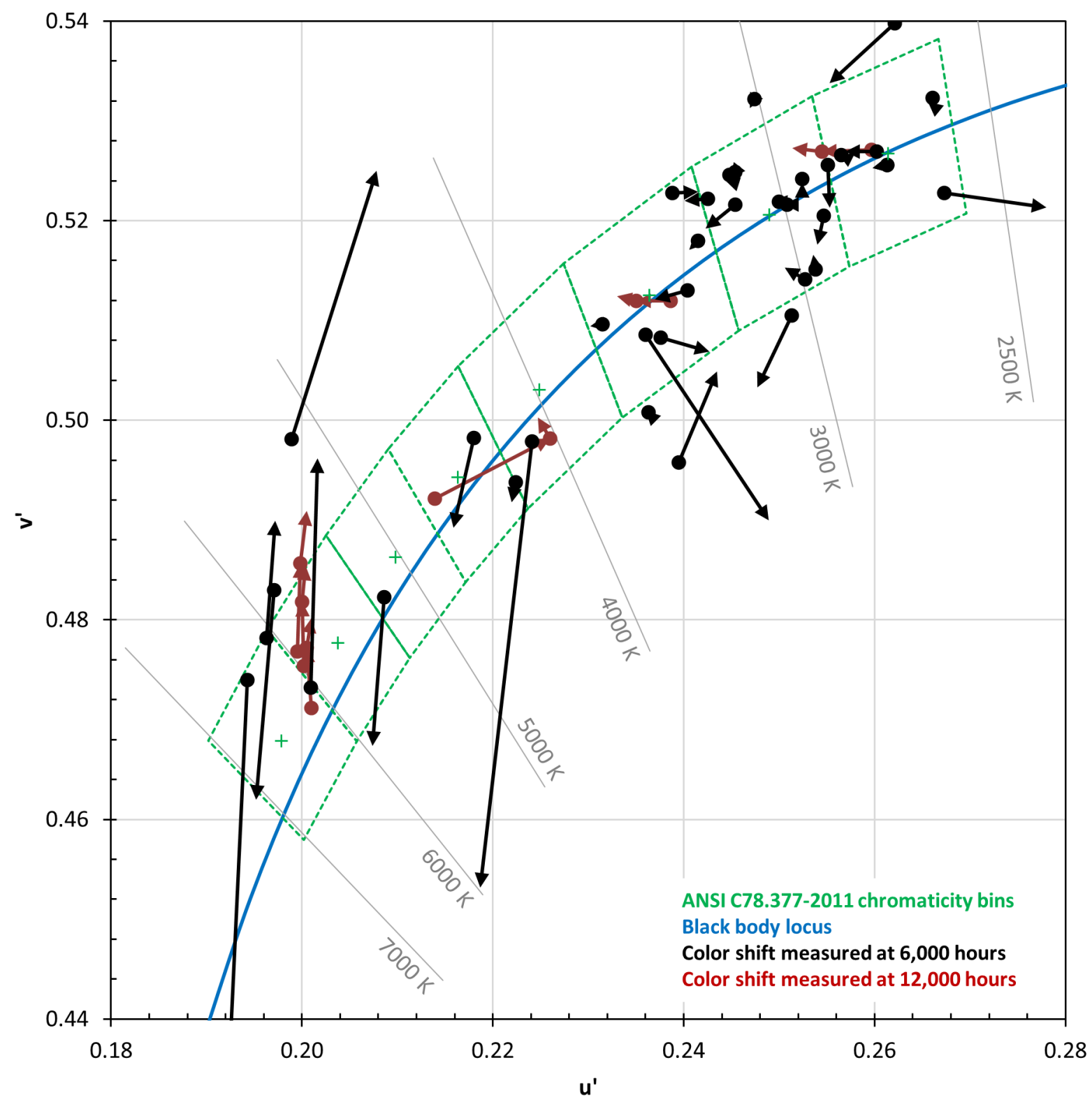

Figure 8. Initial and final chromaticity of lamps tested by CALiPER in 2008-2010.

- Of the seven products using an RGB (red, green, blue) or hybrid approach to making white light, two exceeded a $\Delta u^{\prime} v^{\prime}$ of 0.007 , a similar proportion to the total group.

- Of the seven products that underwent a second 6,000-hour test period, six had a $\Delta u^{\prime} v^{\prime}$ exceeding 0.007 by the end; only two exceeded that threshold after the first period. These products were the oldest-and some of the earliest-LED products on the market, purchased by CALIPER in 2006 or 2007.

- The most extreme shift was for an undercabinet luminaire, which had a $\Delta u^{\prime} v^{\prime}$ of 0.045 at 7,500 hours. Several other products exceeded a $\Delta u^{\prime} v^{\prime}$ of 0.020 , which is nearly three times the ENERGY STAR limit and likely unacceptable for any lighting application. 
Figure 9 shows data for a subset of the products shown in Figure 8 that had intermediate measurements taken every 500 hours using a handheld meter. As shown, a product's chromaticity may not follow a continuous, straight path from the initial measurement to the 6,000-hour measurement. The behavior of the products was often erratic, sometimes reversing course in the middle of testing. This pattern suggests that more than one mechanism of color shift may be at work. However, it is important to note that this data was collected using a less precise meter and in an environment with less rigorous control. The environment may more closely resemble typical operating conditions, but it can make it difficult to separate out color shift caused by thermal changes from color shift caused by physical changes over time.

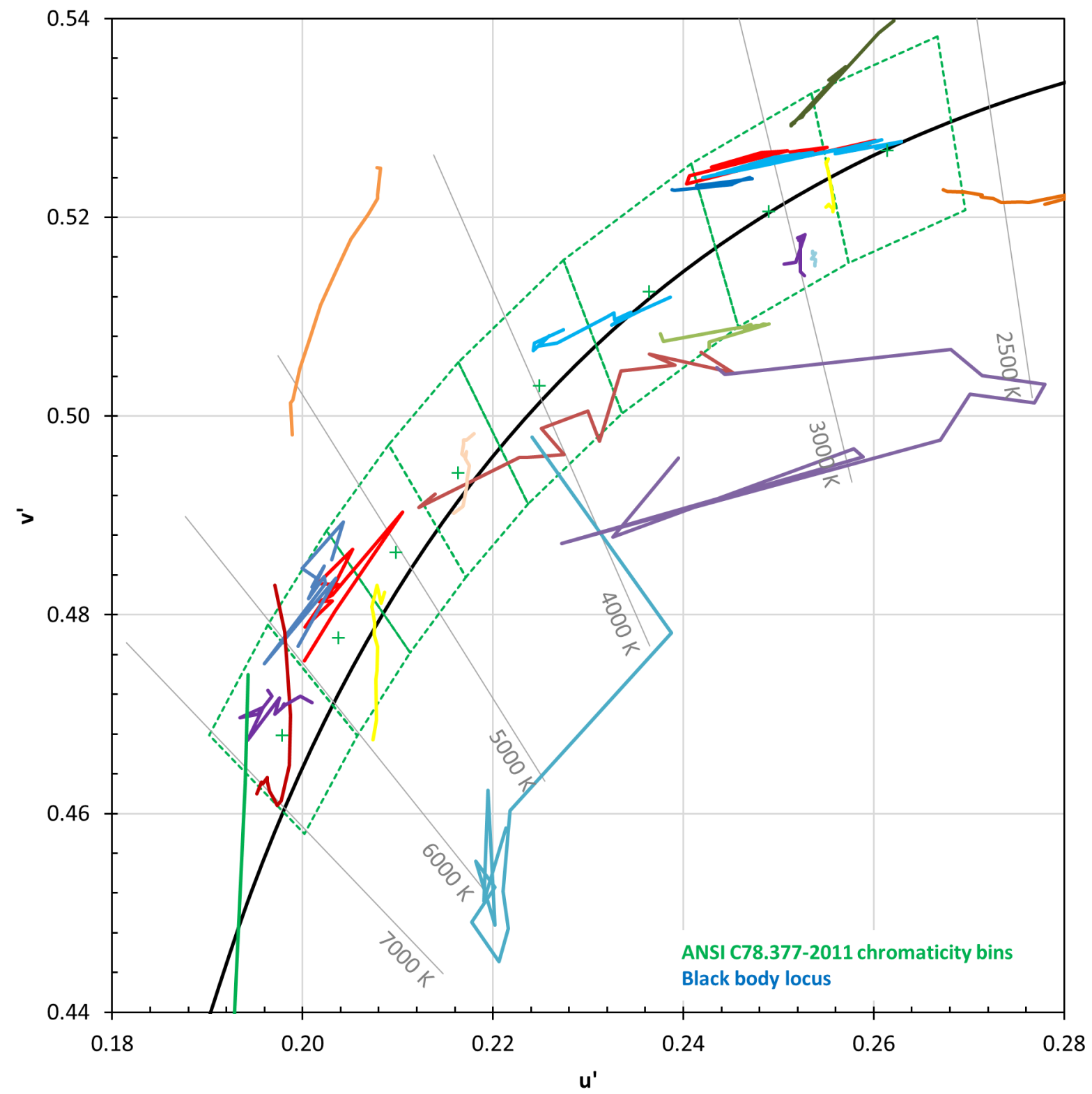

Figure 9. Chromaticity over time for a subset of the lamps shown in Figure 8. When intermediate points are shown, the color shift appears much less predictable. 


\section{DOE L Prize Program Data}

The L Prize-winning A lamp has become one of the most-tested LED products to date. As of April 29, 2013 , a large sample of prototype lamps $(n=202)$ had undergone 25,000 consecutive hours of operation at a target maintained ambient temperature of $45^{\circ} \mathrm{C}$. One piece of the data collected at regular intervals during that time was the spectral power distribution-and thus chromaticity and color shift.

Notably, the L Prize lamp uses remote phosphor technology, in which the phosphor used to create white light is not incorporated directly into the LED package. A minority of LED products uses this approach, and many of the color shift mechanisms discussed in the analysis section of this report are only tangentially relevant to remote phosphor lamps. Additionally, the samples tested were specially built for the evaluation rather than commercial sale. Nonetheless, these data are included to highlight the potential of LED technology.

Contrary to the GATEWAY products and some of the CALIPER products included in this report, the $L$ Prize-winning lamp has shown remarkably little color shift over its lifetime. Although always minimal, the precise magnitude of the shift depends on the analysis method. For this report, the baseline value for each sample was the measurement taken at 22 hours of operation. Additionally, the average $\Delta u^{\prime} v^{\prime}$ value was calculated as the mean of $\Delta u^{\prime} v^{\prime}$ for each lamp, rather than the $\Delta u^{\prime} v^{\prime}$ for the mean chromaticity coordinates at each measurement interval. Selecting a different baseline measurement or using a different averaging method would not alter the general conclusions, even if the precise values differ somewhat.

One important consideration is the dependence of chromaticity on ambient air temperature. Although the $L$ Prize lamps were operated in a special environmental chamber, some variation did occur over the 25,000-hour measurement period. Specifically, there were a few measurement points that clearly appeared to be anomalies, as they were substantially different from the preceding and proceeding measurements. For example, the average $\Delta u^{\prime} v$ ' for measurements taken at 17,106 hours-when the temperature of the sphere dipped approximately $4^{\circ} \mathrm{C}$-was approximately 0.001 higher than the mean measurements immediately before and after. The temperature dependence of the color shift measurements is shown in Figure 10. This attribute is important to understand when attempting to

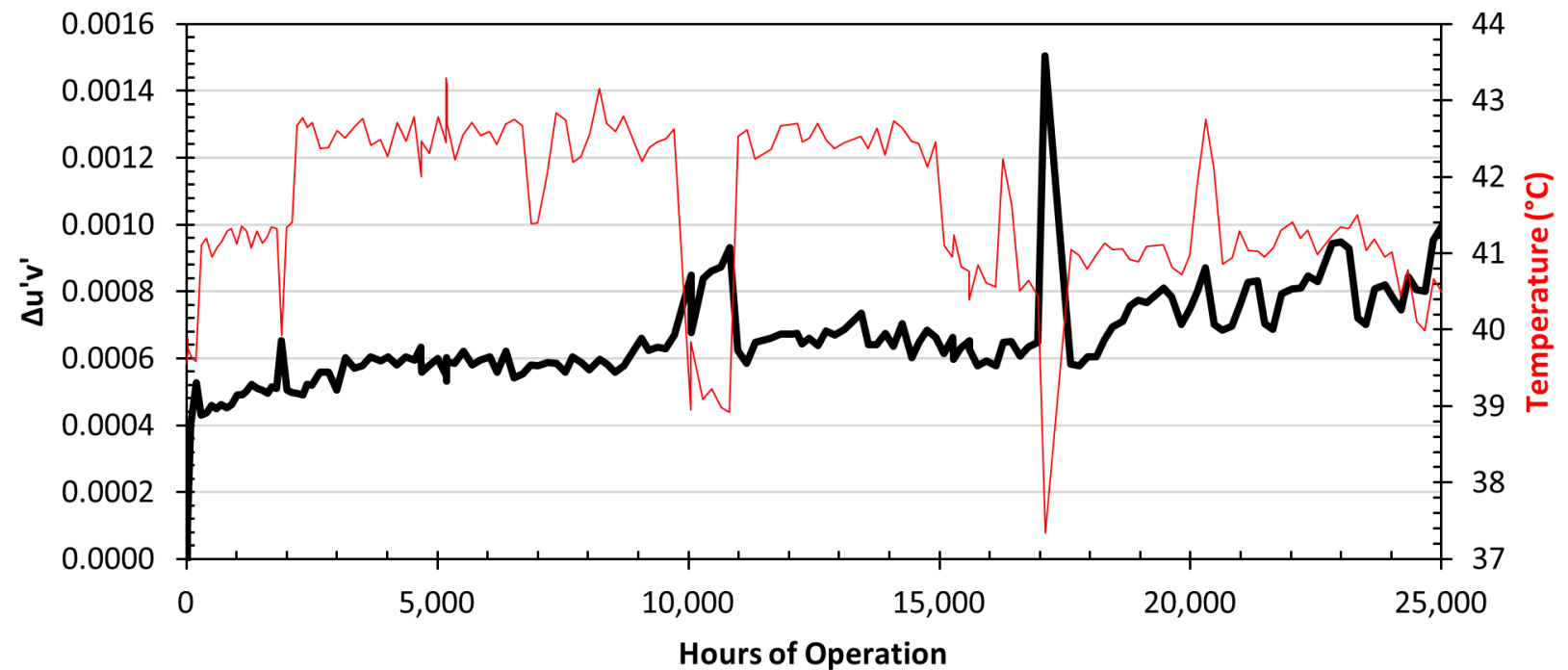

Figure 10. Mean $\Delta u^{\prime} v^{\prime}$ over time versus the temperature of the integrating sphere used for measurement. The temperature at the sphere does not identically match the temperature of the air surrounding the lamps, due to stratification within the apparatus, but the relationship is still apparent. 
make field measurements of color shift, and also provides a baseline for performance expectations in a real installation. Measurements deemed to be influenced by thermal anomalies were removed from subsequent analyses; in charts, those areas are shaded gray.

Excluding times of thermal anomalies, average $\Delta u^{\prime} v^{\prime}$ values remained at or below 0.001 for the entire duration of measurement, as shown in Figure 11 (black line). The highest recorded $\Delta u^{\prime} v$ ' for any of the lamps was 0.0047 (orange line), although this was a large spike that was not seen for any of the other samples. The $\Delta u^{\prime} v^{\prime}$ for that sample, Q7, was less than 0.001 at 25,000 hours. The lamp sample with the highest mean $\Delta u^{\prime} v^{\prime}$ and highest value at 25,000 hours was F4 (red line). This performance was also atypical, with only one other lamp (L5) performing similarly. In contrast, lamp C12 (blue line) had the lowest mean $\Delta u^{\prime} v^{\prime}$, and a maximum $\Delta u^{\prime} v^{\prime}$ of just 0.0006 , which is more than 10 times lower than the ENERGY STAR criterion. Further, sample A12 (green line) had a $\Delta u^{\prime} v^{\prime}$ at 25,000 hours of just 0.0002 , the lowest of any of the samples-although it did drift slightly away from its start point in the first third of the measurement period before coming back.

Although it is not the subject of this report, it is important to understand the color consistency of the $L$ Prize lamps, as it gives context to the color shift data. Figure 12 shows the chromaticity coordinates of all 202 lamp samples at the baseline and 25,000-hour measurements. Although not numerically quantified, it is clear that the trend is for shifts slightly toward blue. Also important is the fact that the magnitude of difference within either the initial or final chromaticity measurements far exceeds the change in chromaticity measured for any of the lamps. That is, the spread of initial or final chromaticity coordinates, with a $\Delta u^{\prime} v^{\prime}$ for the extreme points of approximately 0.006 , is greater than for any of the shifts measured over time for an individual lamp.

Figure 13 shows the chromaticity of six individual L Prize test samples that have different shift characteristics. Although the overall trend was a shift toward blue (lower u' values), this was not the

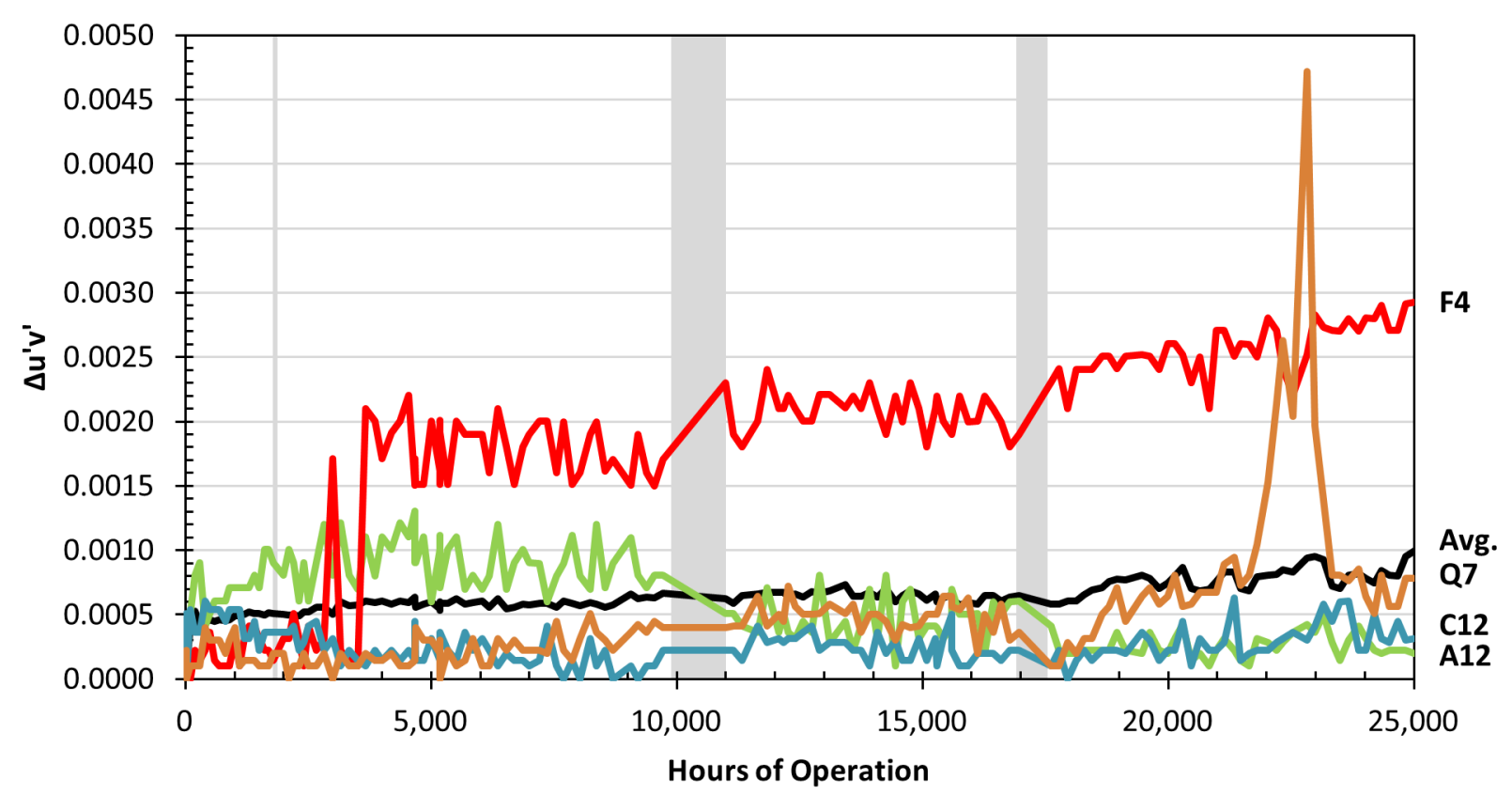

Figure 11. $\Delta u^{\prime} v^{\prime}$ for the best and worst performing lamps. Gray areas indicate data that has been removed due to thermal anomalies. 

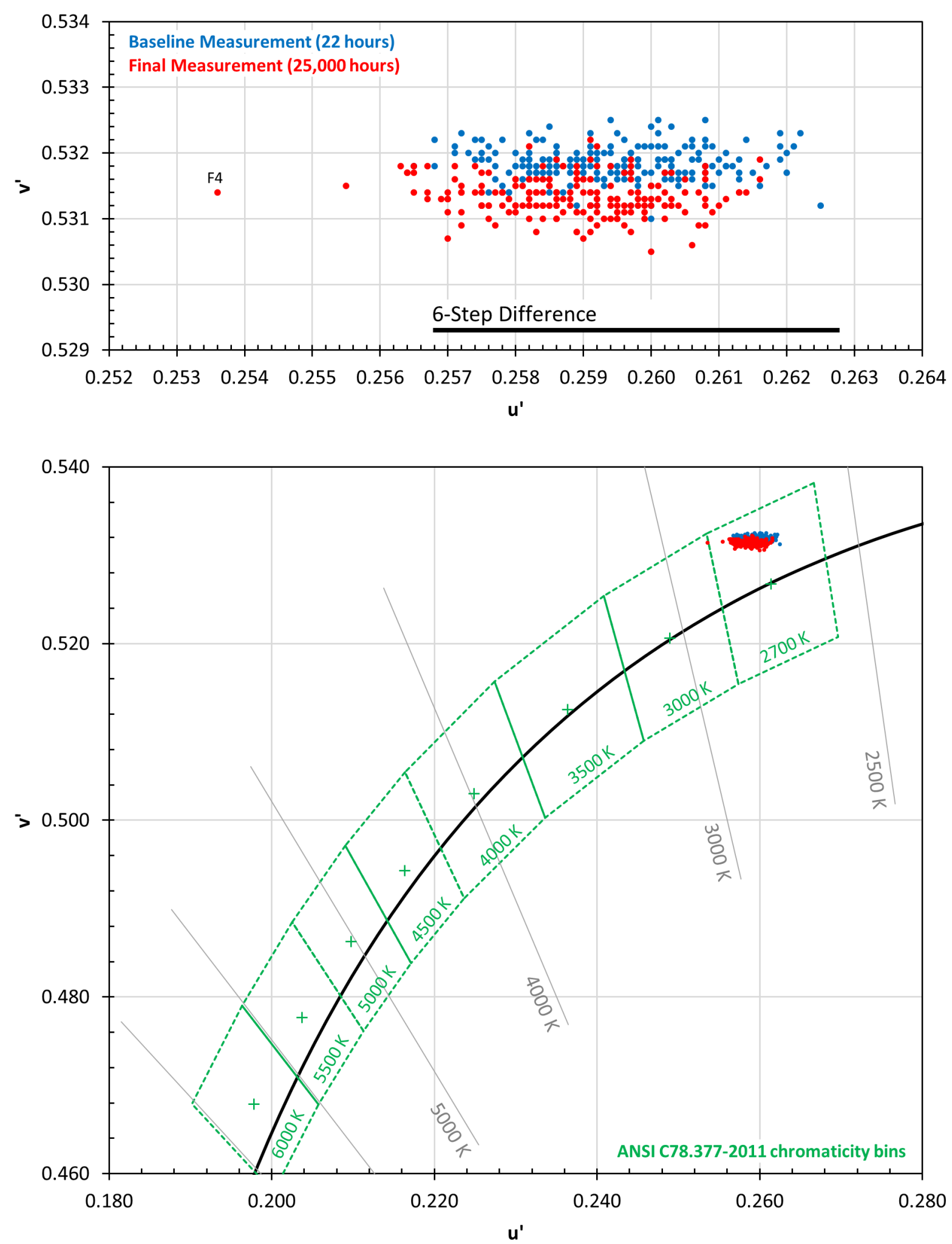

Figure 12. Baseline and final (25,000-hour) chromaticity coordinates for each lamp sample, shown at two different scales of the same plot. 
A5

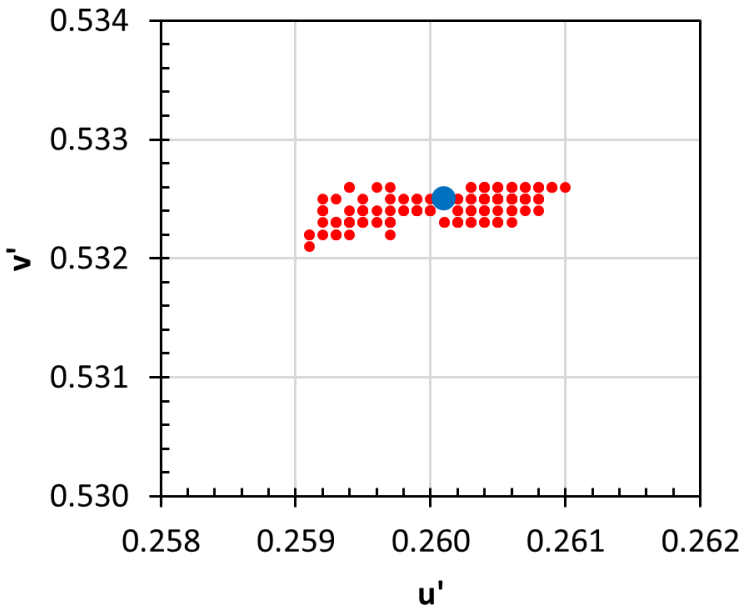

A12

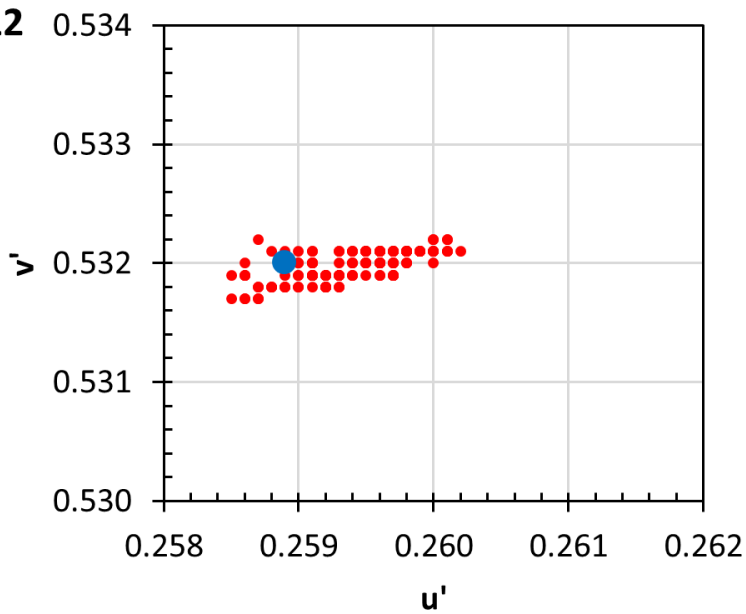

C1

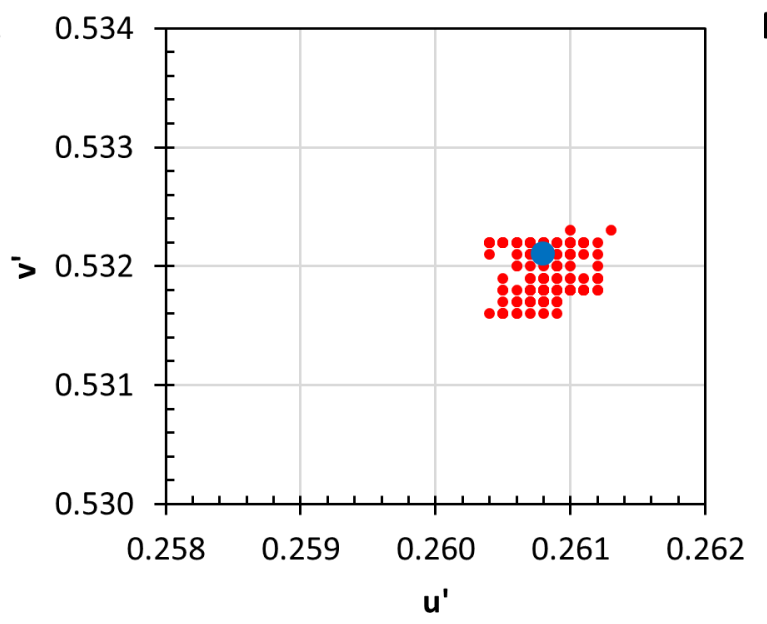

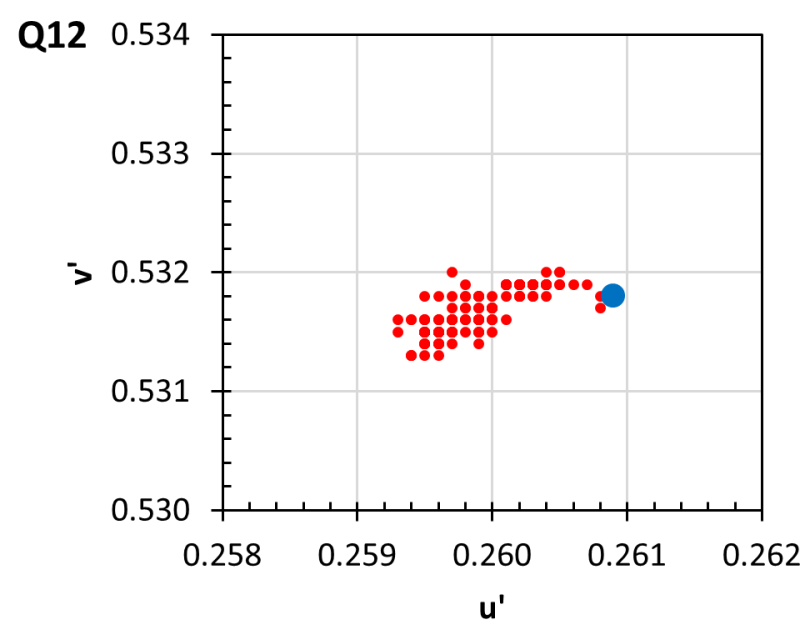

F4*

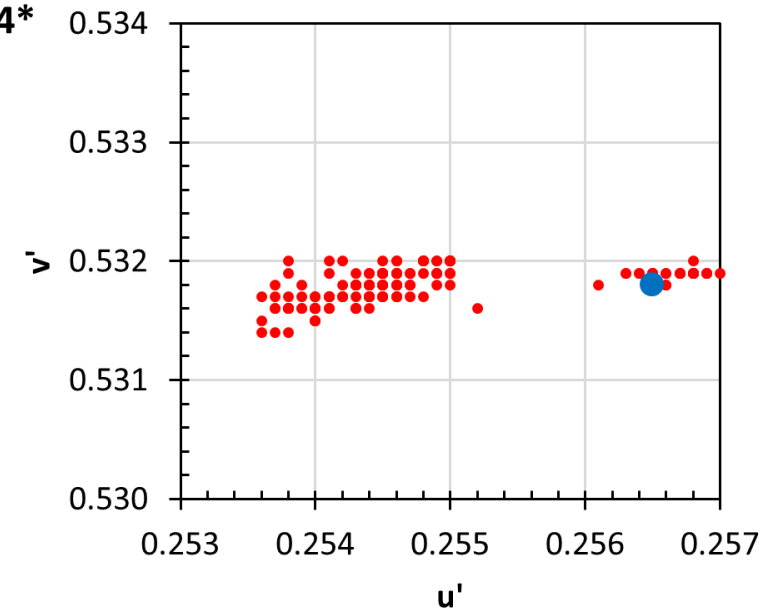

P11

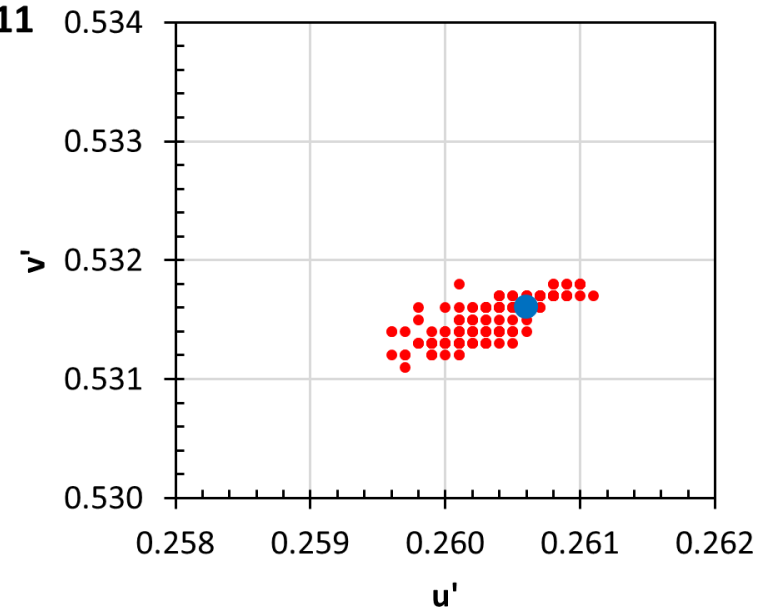

Figure 13. Chromaticity coordinates for six of the sample L Prize lamps. The baseline measurements are shown in blue, and subsequent measurements in red.

*The plot for sample F4 does not have the same axes.

case for all samples - the starting point is marked by the larger blue circle. The exact direction and magnitude of the shift was variable, although it was predominantly along the $u$ ' axis (approximately blue-yellow). 
Importantly, a tolerance must be applied to the measurement device, as well as to the thermal stability of the apparatus. This measurement noise is difficult to quantify, but it likely increases the observed level of variation. Undoubtedly, the color stability of the L Prize lamp is very good and illustrates the high potential for LED products. 


\section{Discussion}

Mechanisms of Color Shift: Operating Conditions

LED product characteristics-including luminous flux, chromaticity, and efficacy-are dependent on operating conditions. LED packages are typically tested and binned by the manufacturer at a specific temperature (e.g., $25^{\circ} \mathrm{C}$ or $85^{\circ} \mathrm{C}$ ) and specific drive current (e.g., $350 \mathrm{~mA}$ ). If the LEDs are used in an application where the temperature and/or drive current differs from what was used during the product testing, then the chromaticity can be different. The magnitude of chromaticity shift with temperature and current changes will differ from one manufacturer to another, as the technologies used to fabricate the LEDs will each be different. In some cases, the shifts are so small as to be unnoticeable, whereas in other cases the shifts are very significant.

For LED products, color shifts caused by changes in the operating conditions are generally recoverable. That is, if the change is reversed, the chromaticity should return to its original point. This is not unlike some conventional technologies, such as fluorescent, and there is probably little opportunity to alter the behavior. While users should be aware of color shift due to changes in operating conditions, the greater concern for the lighting industry is reducing or eliminating changes that stem from premature physical degradation. The data presented in this paper were all for lamps in steady-state operation, and the ambient conditions did not substantially change.

It should be noted that there might be long-term consequences from operating at a higher temperature, because heat generally increases the degradation of materials. Similarly, on-off cycling-and the associated thermal changes - may have some unrecoverable effect on the physical materials of an LED package. Such an effect would not be accounted for in LM-80-08 testing of LED chips. In short, changes due to operating conditions and physical changes causing color shift are not entirely independent.

Another aspect of color shift is its relation to dimming. LED products may or may not change chromaticity when dimmed, and this behavior may or may not be intentional or desired. In general, this is a separate issue from color stability at steady-state operating conditions.

\section{Mechanisms of Color Shift: Physical Changes to LED Packages}

The most commonly available LED packages are a combination of a "blue" LED and "yellow" phosphorin reality, the blue LED emits energy over a narrow range of wavelengths, while the phosphor downconverts some of the emitted blue to radiant energy having a wide range of wavelengths, including those perceived as green, yellow, orange, and red. The combination appears nominally white. These LED packages are often referred to as phosphor-coated (PC) LEDs. Other LED packages or arrays use a combination of discrete LEDs (e.g., red, green, and blue) that are mixed to create white light, and still others use a hybrid approach that adds an additional discrete LED (usually red) to a PC-white LED package.

The focus of the subsequent discussion is on typical PC LEDs. Many of the issues discussed here also apply to hybrid or color-mixed LED packages, although the additional diode(s) may add another mechanism(s) of instability. Specifically, the different colored diodes can each degrade differently over time. Integrating the output from multiple colored LEDs can also pose a challenge for color uniformity, especially for products with narrower distributions. Remote phosphor products, like the L Prize lamp, are fewer in number and likely have different mechanisms of color shift. The L Prize lamp is one carefully engineered example of a remote phosphor lamp with excellent color stability, but as with other product types, variation in performance is likely substantial. 
PC LEDs come in a wide variety of physical forms that have consistently evolved as LED technology has matured. Long-term performance can be difficult to assess, given the length of time needed for measurements, and significant problems may only arise after prolonged field use. At the package level, several changes can occur that result in the emitted light typically shifting toward either yellow or blue. The exact mechanism is primarily based on the type of package. The following are several examples, but the list is not exhaustive and there is large variability from manufacturer to manufacturer and product to product:

- Some (early-generation) LED packages mixed the phosphor with a soft silicone and dispensed it into a reflector cavity (Figure 14). Over time, the phosphor particles were found to settle, allowing more blue photons to be emitted from the package without conversion to longer wavelengths. The result was a severe shift toward the blue end of the spectrum.

- Most low- and mid-power plastic LED packages use a similar mixing method to the one described previously, but the silicones used in these products tend to be much firmer. As a result, the particles do not settle in the package; however, there is potential for color shift to result from discoloration of the plastic (Figure 15). Polyphthalamide (PPA) is a common plastic resin used in LEDs that is known to discolor at high temperatures and when exposed to shortwavelength radiant energy.

- Another type of LED package coats the phosphor in a thin layer on the top surface of the chip, with silicone molded over top (Figure 16). With one type of coating technology, the phosphor layer can curl up at the edges of the chip, resulting in blue photons being emitted at high angles without conversion to longer wavelengths (Figure 16a). A shift toward blue is then observed. With other coated-chip products, delamination of the phosphor from the surface of the chip can occur at high temperatures (Figure 16b). The resulting air gap between the chip and the phosphor increases the angle at which the blue photons pass through the phosphor, and the resulting mean free path of the blue photons through the phosphor increases, causing a shift toward yellow. Better attachment methods in more recent products have helped to alleviate these problems. Color shift characteristics for several coated LED packages, both older and newer, are shown in Figure 17.

- In some of the newest LED packages, phosphor is applied to the entire package surface, including the chip and substrate (Figure 18). This can further alleviate the curling and delamination problems, greatly increasing color stability. As with any of the package types described in this report, there is substantial variation from one product type to the next; the example data provided does not represent every product. Further, the data does not represent an endorsement of any package technology, but is simply meant to illustrate the wide variety of products that are available and the potential for color stability issues.
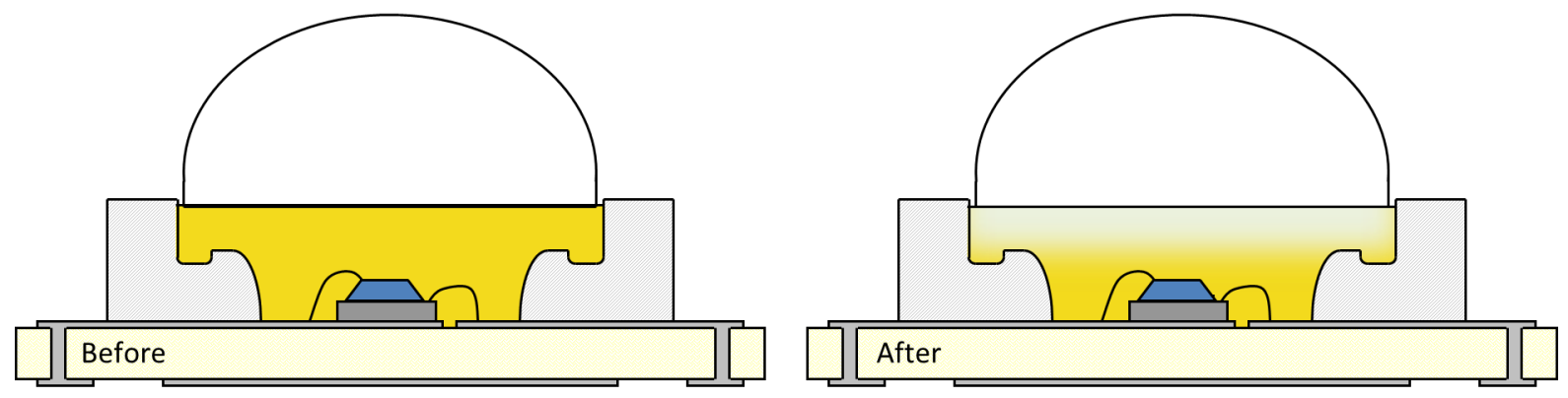

Figure 14. For some early-generation LEDs, phosphor mixed with silicone settled over time. 

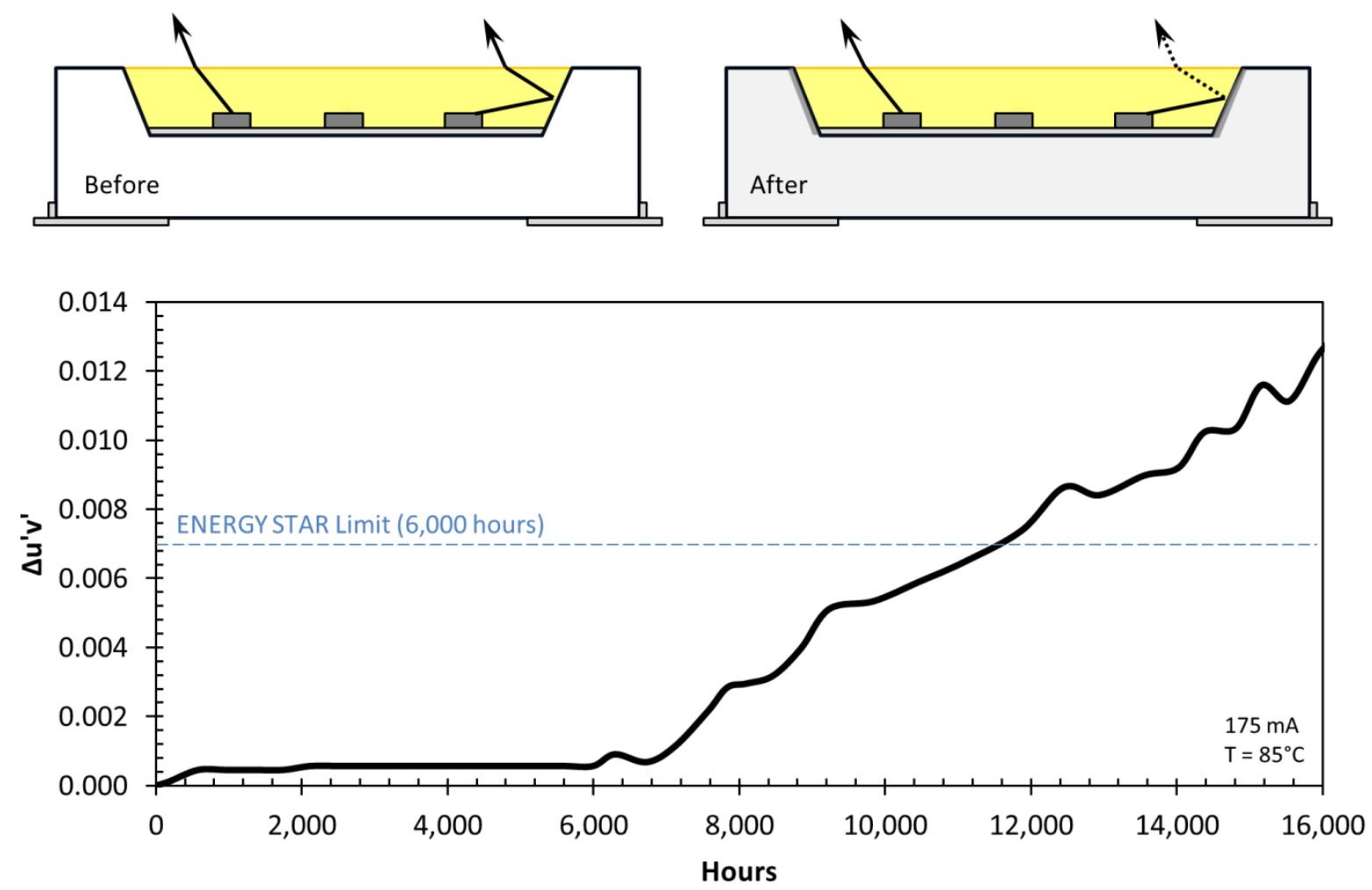

Figure 15. Some low- and mid-power LED packages can shift color because the plastic housing discolors. The diagrams above illustrate that some of the light emitted from the die that would reflect off the housing may be absorbed or shifted if the plastic discolors, thus changing the overall emission from the package. The plot below shows the average shift for a sample of one type of product. The ENERGY STAR criterion is shown for reference only.

LED package technology is constantly changing and improving, with the ultimate goal of a package that is physically stable from start to end. However, the latest and greatest LEDs do not make it into every final product, and there is often a substantial lag between chip development and deployment in end-use lamps and luminaires. It can be very difficult for end-users to know what generation or type of LED is included in a product without asking manufacturers detailed questions. This issue is exacerbated when manufacturers make subtle changes to improve performance but do not re-label the new products to indicate a new design.

Adding another layer of complexity beyond changes to the packages, the materials used for primary or secondary optics may change over time. In some products (e.g., $5 \mathrm{~mm}$ radial lamps), epoxy is used as an encapsulant. Over time, discoloration of the epoxy is frequently observed. Likewise, manufacturers must carefully select the materials used for optical components or risk discoloration, because many chemicals, especially adhesives, used in the manufacturing of lamps and luminaires can be unstable during operation. In many cases, the lamp or luminaire manufacturer is different from the LED package manufacturer. This can make understanding the cause of observed color shift more difficult, and warranty claims more complicated.

Physical changes may also occur in the driver, which could result in a different drive current, which in turn might cause color shift. This issue has not yet been extensively investigated; however, it may be a contributing factor to differences between LM-80-08 color shift data for LED chips and the color shift data for complete products described in this report. 

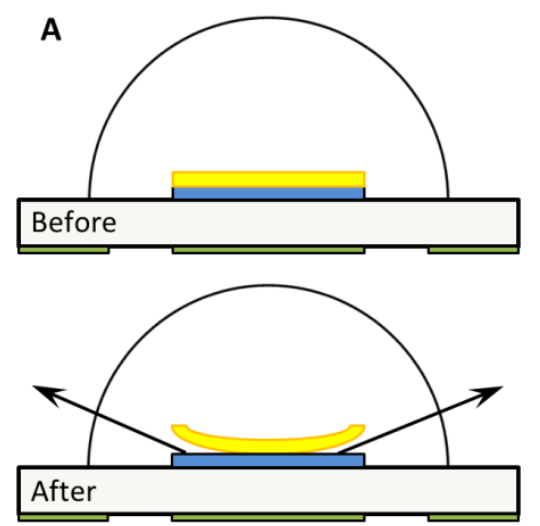

Figure 16. Curling (A) and delaminating (B, close up) are two potential causes of color shift with phosphor-coated LED packages. Curling generally causes a shift toward blue, whereas delaminating generally causes a shift toward yellow.
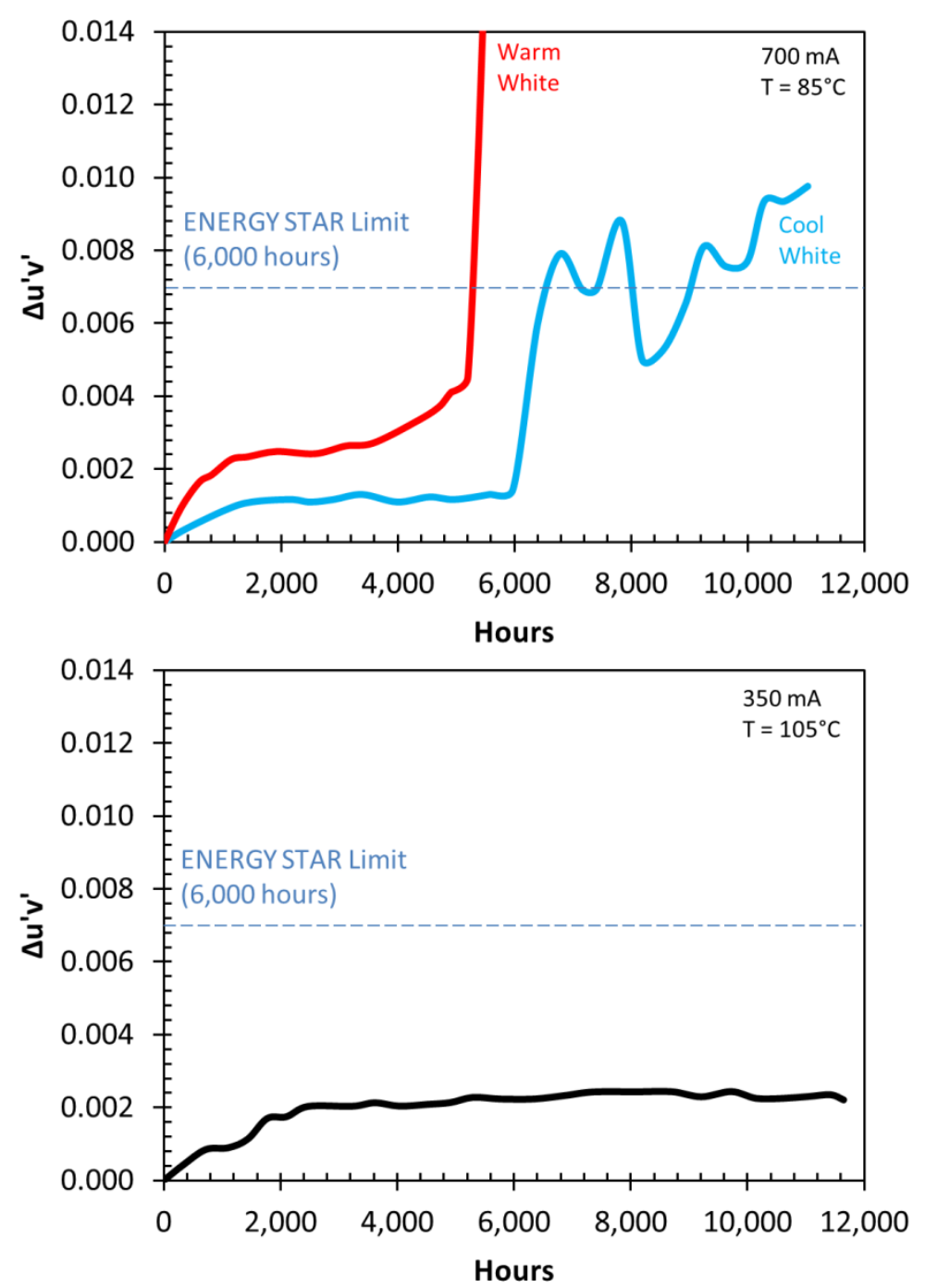

Figure 17. Top: Some older phosphor-coated LED packages exhibited rapid color shift after several thousand hours of operation. Bottom: An example of a newer phosphor-coated LED package with very good color stability. Both plots show the average color shift for a sample of lamps.

\section{Comparisons to Conventional Products}

Color consistency and color stability can vary greatly with different technologies. Incandescent lamps, including halogen variants, generally have good color stability, and some specifiers and users like the fact that they shift to a warmer color when dimmed. In contrast, metal halide lamps are notorious for having very unstable color. Besides substantial shifts early in life, chromaticity may change on the order of $\Delta u^{\prime} v^{\prime}=0.020$ over a lamp's lifetime [NLPIP 2004]. Ceramic metal halide lamps offer some improvement. Due to their poor color stability, metal halide lamps are rarely used in applications where color quality and color stability are critical.

In general, color stability for fluorescent lamps is considered very good, with typical changes over a majority of life less than a $\Delta u^{\prime} v$ ' of 0.004 . However, fluorescent lamps do not always have good color consistency; that is, fluorescent lamps from different manufacturers with the same listed CCT can have a wide range of measured chromaticities. More importantly, output is strongly affected by ambient temperature.

Fluorescent lamps are almost exclusively used for general ambient lighting, where color tolerances are not always high and where slight variations among lamps are less noticeable because the light from many lamps is mixed together in the final lighted environment. Many of the tolerances established for LED lamps came from previous tolerances established for 


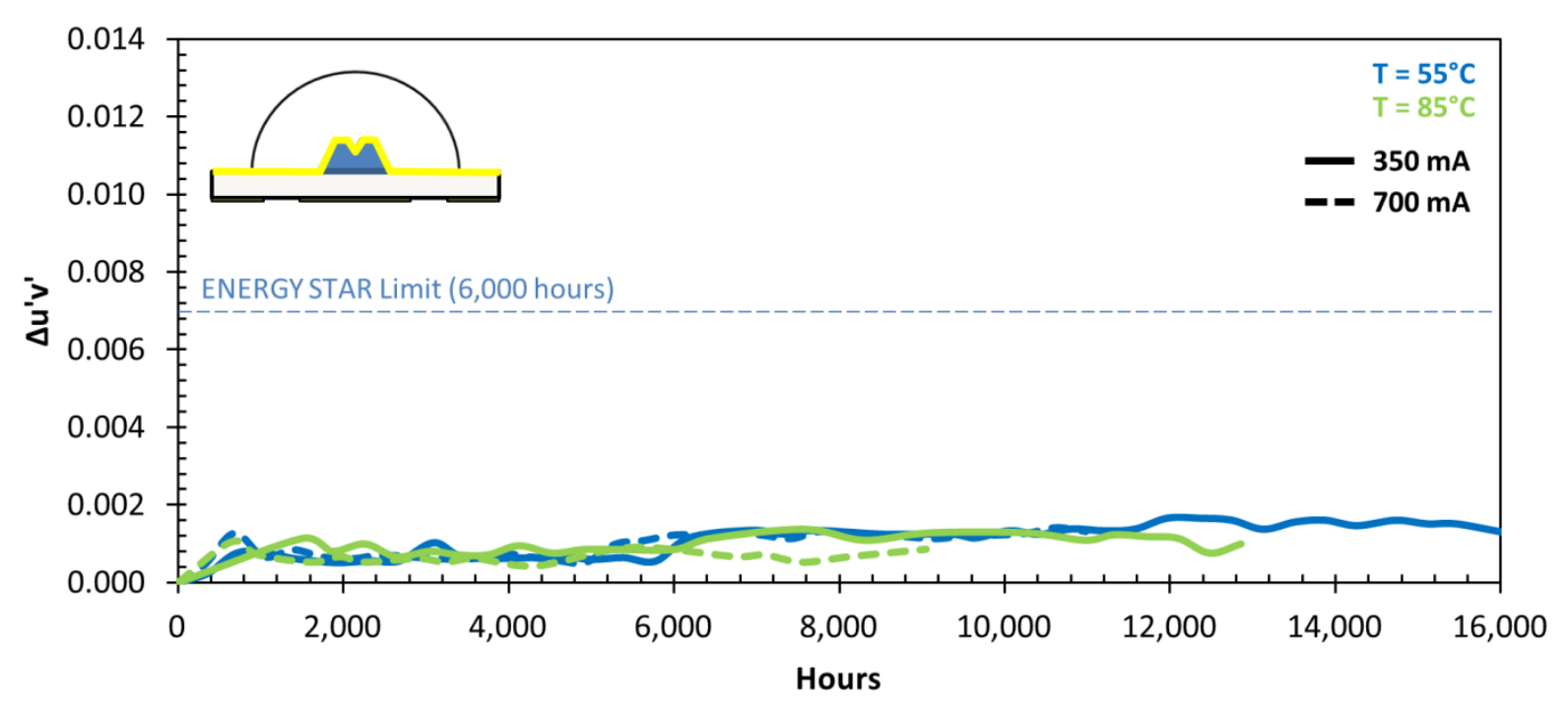

Figure 18. Average color shift for a newer type of LED package that has been measured to have very good color stability under several different operating conditions.

fluorescent lamps; for example, the IES/ANSI quadrangles defined in C78.377-20111 were derived from seven-step MacAdam ellipses used to define nominal CCTs for compact fluorescent lamps (ANSI C78.376-2011) [ANSI 2001].

There has been some debate over the need for more stringent color tolerances for LED products than for incumbent conventional technologies - from ENERGY STAR or other programs. This is driven largely by the lofty potential of LED products, rather than by actual user experiences to date. In general, stricter tolerances for color stability may only be needed in specific applications, and may not be needed for most general lighting.

\section{Warranty Issues}

Although color shift is a known cause of parametric failure for LED sources-much like lumen depreciation-it is covered by only a small number of manufacturers' standard warranties. This could partially be attributable to the difficulty in predicting color shift from measured data, and as a result, many existing warranties cover only the period of LM-80-08 measurement (e.g., 6,000 hours). As shown in Figures 15 and 17, however, color shift may only become a problem after that time. Nonetheless, at a minimum, manufacturers should warranty that $\Delta u^{\prime} v$ ' should not exceed 0.007 at 6,000 hours, especially for ENERGY STAR-qualified products. This is likely the minimum quality standard for any interior architectural lighting.

One consideration with color shift warranties is what to use as the baseline measurement from which $\Delta u^{\prime} v$ ' can be calculated. Moreover, it must be established whether the color shift is relative to a baseline for each lamp or is relative to other lamps of the same type operated for the same number of hours. In other words, is the situation where all lamps change in the same way considered a failure? Finally, manufacturers should clearly state any restrictions that apply, such as operating a lamp in an enclosed luminaire, or above a certain ambient temperature. If restrictions are based on the junction temperature not exceeding a certain limit, the manufacturer should communicate a procedure by which users can ensure they are meeting the terms of the warranty. For example, some manufacturers provide a temperature measurement point (Figure 19) on the lamp and indicate the maximum allowable 


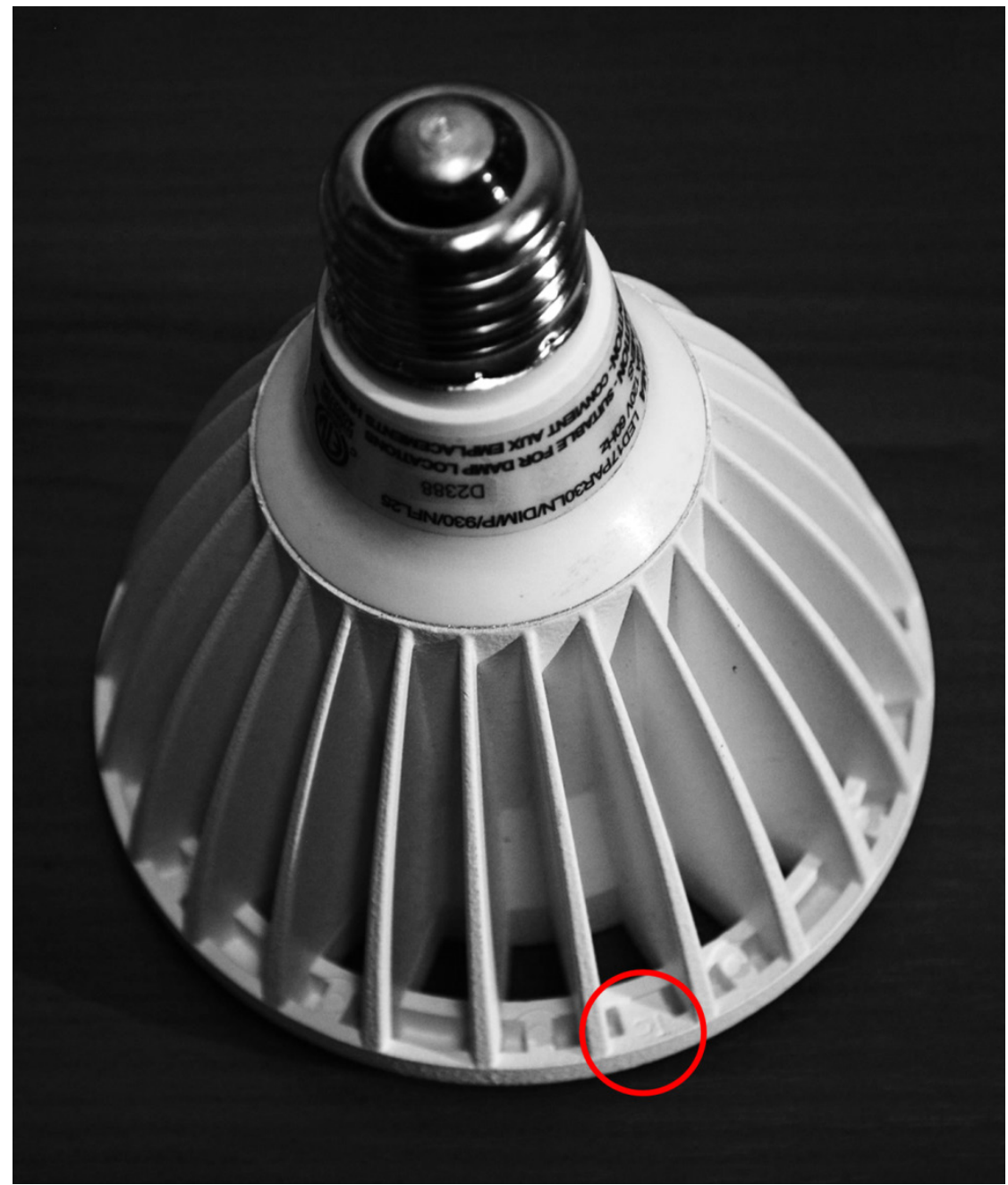

Figure 19. A temperature measurement point, marked Tc, is shown on an example lamp. temperature at that point.

This information is helpful to

fixture manufacturers that must design appropriate airflow or other forms of thermal management.

\section{Best Practices for Monitoring Color Shift}

Often, potential color shift is overlooked at the time of installation, with concern arising later, when there is visible evidence of change. However, it is very important to begin monitoring color at the time of installation, or at least take actions to allow for investigation at a later time.

The simplest, and crudest, way for consumers to track color change is to keep a minimum of two products in storage as a reference for post-hoc measurements. It is important to make sure that all products, including the reference(s), match color as closely as is required for the application at the time of installation. It is also

important to record the installation date for each lamp, track or estimate hours of use, and keep the invoice showing where and when the products were purchased.

In critical applications, like museums, or for scientific demonstration projects, a proactive approach may be more valuable, especially if warranties include color shift as a failure mechanism. Ideally, regular measurements would be taken of the same product according to LM-79-08; however, this would likely be prohibitively laborious and expensive. Alternatively, an initial LM-79 measurement could be used to establish a baseline. ${ }^{4}$ Subsequently, spot measurements with a handheld meter may be used to track changes. It is likely that the measurements made with the handheld meter will not exactly match those made using an integrating sphere and following the LM-79-08 procedure; ${ }^{5}$ however, these spot measurements may help to identify if and when an unacceptable color shift has occurred. At this point, a follow-up measurement can be made in a photometric laboratory, if necessary.

\footnotetext{
${ }^{4}$ Because the output can change substantially in early life, taking a baseline measurement at 0,100 , and 1,000 hours may be a preferred approach, if possible.

${ }^{5}$ Both differences in operating conditions (e.g., ambient air temperature, lamp tilt) and differences in metering equipment may contribute to differences in measured chromaticity.
} 
In many cases, even one LM-79-08 measurement may not be feasible-or beyond the budget of the specifier or building owner. In such cases, monitoring chromaticity with a handheld meter or comparing used lamps with new lamps may be the only options. These practices can help identify a problem, but their relevance to making a warranty claim should be addressed with the manufacturer prior to purchase.

\section{Future Developments}

As with many aspects of LED performance, there is substantial need for accelerated testing to predict color shift. The reliability of such calculations is presently a concern, although the IES has initiated a committee that will be charged with developing an approved procedure. This work is targeted toward LED packages, for which the exact operating characteristics are more easily controlled. Much like lifetime and reliability, extending component-level data to complete LED lamps and luminaires can be difficult.

In the meantime, the lighting industry should pay increased attention to the issue of color shift, which could lead to unacceptable levels of end user dissatisfaction with the technology. It is clear that the color stability of LED packages is improving, but more work is needed to communicate performance between different segments of the industry. Greater education on the metrics and language used to describe color shift would help to facilitate higher-level discussions.

As the issue of color shift has become more widely known, some manufactures are beginning to respond by expanding warranty coverage. However, at this time there is no standardized threshold for acceptability - such as $L_{70}$ for lumen maintenance-beyond what is specified by qualification programs like ENERGY STAR. Furthermore, there is no standardized method for users to measure or document color shift, which may make the warranty claim process confusing or overly burdensome. In the future, harmonized warranty procedures and coverage may help alleviate specifier concerns stemming from the large variation between different products, and provide assurance until better-performing products permeate the market. 


\section{Conclusions}

Improving the long-term color stability of LED products is highly desirable, lest they be relegated to limited applications where color shift is not a concern. Data collected by multiple DOE SSL programs suggests that the performance of some products is closer to that of metal halide lamps than to fluorescent or halogen lamps, but also suggests that some LED products offer excellent color stability.

Many factors contribute to the variation in color maintenance performance of LED lamps and luminaires, including the construction of the LED packages themselves. In the past few years, several generations of packages have been developed by numerous manufacturers. Over that time, much has been learned about the long-term color stability of products, and improvements have been made. However, the newest generations of LED packages do not have full market penetration, nor are they all immune to color shift. Thus, end-users who are concerned about color stability must be especially careful in choosing a product; however, it is difficult to predict which products might have better color stability, even when one is aware of the issue and well versed in the technical details.

As GATEWAY and CALiPER data have shown, color shift is especially complicated the complete product level, with numerous contributing factors. As a result, in applications where color quality is important, some products have useful lifetimes that are substantially shorter than their rated lifetime, which may in turn affect the anticipated payback. These concerns could be alleviated with manufacturer warranties, but there are few currently available warranties that cover color shift.

Future work on color shift should include:

1. Continued development of LED package technology to improve color stability.

2. Development of standards for predicting long-term color shift performance from a more limited set of measured data.

3. Investigation of the interaction of multiple factors affecting the color stability of complete LED lamps and luminaires.

4. Education within all segments of the lighting industry regarding the issue of color shift and the tools to communicate it properly.

5. More widespread inclusion of color shift in product warranties, pursuant to an agreed-upon method for documenting color shift beyond an established threshold.

As more and more LED products are installed in buildings and the hours of use continue to grow, longterm performance issues such as color shift will become more prominent. While it may be convenient to overlook color stability in favor of improved efficacy or lumen output at the time of installation, the ability of LED products to achieve satisfactory performance over time will contribute greatly to their increased adoption. The capability for excellent color stability has already been demonstrated; as LED technology continues to develop, there should be no need to compromise color stability for other performance attributes. 


\section{References}

[ANSI] American National Standards Institute. 2011. ANSI_ANSLG C78.377-2011. American National Standard for electric lamps: specifications for the chromaticity of solid state lighting products. Rosslyn, VA: National Electrical Manufacturers Association.

[ANSI] American National Standards Institute. 2004. ANSI C78.376-2001. American National Standard for electric lamps: specifications for the chromaticity fluorescent lamps. Rosslyn, VA: National Electrical Manufacturers Association.

[CIE] International Commission on Illumination. 2004. CIE 15-2004. Colorimetry. 3rd Edition. 72 p.

[DOE] U.S. Department of Energy. 2012. Demonstration of LED retrofit lamps. Host site: Smithsonian American Art Museum, Washington, DC. PNNL-21476.

http://apps1.eere.energy.gov/buildings/publications/pdfs/ssl/2012_gateway_smithsonian.pdf

[EPA] Environmental Protection Agency ENERGY STAR Program. 2013. ENERGY STAR program requirements, product specification for lamps (light bulbs); Eligibility criteria version 1.0. 25 p.

[EPA] Environmental Protection Agency ENERGY STAR Program. 2012. ENERGY STAR program requirements for luminaires; Eligibility criteria version 1.1. $36 \mathrm{p}$.

http://www.energystar.gov/ia/partners/product_specs/program_reqs/Final_Luminaires_Program_Requ irements.pdf

[IES] Illuminating Engineering Society. 2008. LM-80-08 IESNA approved method: measuring lumen maintenance of LED light sources. $4 \mathrm{p}$.

[IES] Illuminating Engineering Society. 2011. TM-21-11 Projecting long term lumen maintenance of LED light sources. $25 \mathrm{p}$.

MacAdam, DL. 1942. Visual sensitivities to color differences in daylight. Journal of the Optical Society of America 32(5):247-274.

[NLPIP] National Lighting Product Information Program. 2004. What is color stability? Lighting Answers. October 2004.

http://www.Irc.rpi.edu/programs/nlpip/lightinganswers/lightsources/whatisColorStability.asp

Wyszecki G, Stiles WS. 1982. Color science, concepts and methods: quantitative data and formulae. 2nd ed. New York: Wiley; 968 p. 
